\title{
III. DIE JAKOBINISCHE DIKTATUR
}

\section{Die Diktatur der Volksvertreter}

Bereits im März 1793 hatte der von den Volksrepräsentanten aus der Stadt verbannte Michel Thomassin der Nationalversammlung berichtet, daß Straßburg vom Schrecken gelähmt sei. Doch erst als preußisch-österreichische Truppen im Oktober 1793 auf fünfzehn Kilometer an Straßburg herangerückt waren, verdichteten sich einzelne außerordentliche Maßnahmen zu einer veritablen Schreckensherrschaft. Im Herbst 1793 trat die Radikalisierung in eine dritte Phase, die von neuen Konfliktkonstellationen und noch stärker als die vorhergehenden von exklusiven Selbstdefinitionen und verbitterten Feindschaften geprägt war. Die Toleranz gegenüber kultureller Vielfalt verschwand endgültig; aus politischen Einheitsvorstellungen entwickelte sich der Wille zu kultureller Einheitlichkeit. Die Bereitschaft zur Gewalt wurde im staatlichen Terror umgesetzt.

Die Untersuchung der dritten Phase der Radikalisierung beginnt mit einer Analyse der äußeren Einflüsse, denen Straßburg seit dem Sommer 1793 verstärkt ausgesetzt war. Erstens müssen die Auswirkungen von Versorgungskrise und Krieg auf die ideologische Entwicklung in der jakobinischen Führung von Straßburg und auf die Politik der Terreur analysiert werden. Es soll gezeigt werden, daß es rationale und irrationale Formen des Umgangs mit der Bedrohung gab und daß es insbesondere die irrationalen waren, welche die Schreckensherrschaft prägten. Zweitens ist der Einfluß der Représentants $d u$ peuple auf die Radikalisierung zu bestimmen. Der Konvent schickte in einem Zeitraum von eineinhalb Jahren etwa dreißig Emissäre zur Rheinarmee und in die östlichen Départements; die Präsenz der Vertreter der Zentrale wurde 1793 zur Normalität ${ }^{1}$. Sie arbeiteten in einem Spannungsfeld zwischen den Anordnungen der Zentrale, den politischen Glaubensrichtungen der Hauptstadt, den Erfordernissen von Versorgungskrise und Krieg, den lokalen politischen Auseinandersetzungen und ihren eigenen politischen Prinzipien. Welcher von diesen Faktoren ihre Maßnahmen am tiefgreifendsten prägten, soll im folgenden untersucht werden. Vor allem aber müssen ihre vielfältigen Einflüsse auf die Stadt und den Club analysiert werden. Sie brachten nicht nur neue ideologische Impulse nach Straßburg, sondern griffen auch direkt in die Politik der

${ }^{1}$ Michel BIARD, Les pouvoirs des représentants en mission (1793-1795), in: AHRF 70 (1998) S. 3-24. 
Grenzstadt ein. Einerseits setzten sie die lokale Autonomie und Selbstverwaltung außer Kraft, andererseits richteten sie die Institutionen des Terrors ein. Der Einfluß der Repräsentanten war also zweifelsohne sehr stark. Dies darf jedoch nicht den Blick für den Anteil der lokalen Politik an der Genese des Terrors verstellen; die Grenzen der äußeren Einflüsse müssen ebenso untersucht werden wie die Formen der Kooperation zwischen Repräsentanten und lokalen Jakobinern.

\section{Versorgungskrise und Krieg}

Im eigentlich von der Natur gesegneten Osten Frankreichs wurde im Frühjahr und Sommer 1793 das Getreide knapp. Schon zu Anfang des Jahres 1793 konnten die Märkte in Städten und Dörfern die Bedürfnisse der Verbraucher nicht mehr befriedigen. Die Ernte des letzten Jahres ging langsam zur Neige; gleichzeitig wuchs der Bedarf durch die Nähe des Krieges. Auch das mangelnde Vertrauen in die Assignaten, deren Kaufkraft nur noch die Hälfte ihres Nennwerts betrug, hatte Auswirkungen auf die Versorgung. Bereits im Februar 1793 wandten sich die Repräsentanten Couturier und Dentzel, die ursprünglich zur Säuberung der Verwaltungen angereist waren, dem Problem zu. Sie verabschiedeten zusammen mit den örtlichen Verwaltungen einen Erlaß, welcher den Handel mit Assignaten und das doppelte Auspreisen verbot ${ }^{2}$.

Im April spitzte sich die Versorgungskrise zu. Die Assignaten verloren weiter an Wert; mehrere Kommunen und die dort stationierten Truppenteile meldeten das Ende ihrer Nahrungsvorräte ${ }^{3}$. Die im selben Monat zur Rheinarmee entsandten Repräsentanten Soubrany, Haussmann, Ruamps und Maribon-Montaut ${ }^{4}$ berichteten dem Konvent von der unmittelbaren Gefahr einer schweren Versorgungskrise im Elsaß und wiesen darauf hin, welche Folgen dies für die Truppen haben könne ${ }^{5}$. Am 29. April konferierten sie mit den örtlichen Verwaltungen über das Problem. Sie beschlossen jedoch zunächst nur, die Überwachung der Grenzübergänge zu verstärken, um den heimlichen Export von Getreide zu verhindern ${ }^{6}$. Am 1. Mai schließlich reagierten die im El-

${ }^{2}$ Repr. Couturier, Dentzel, Beschluß vom 4. Feb. 1793 [Arch. Nat. Paris, AF II 247, doss. 2107, 6].

${ }^{3}$ Robert WERNER, L'approvisionnement en pain de la population du Bas-Rhin et de l'armée du Rhin pendant la Révolution (1789-1797), Strasbourg, Paris 1951, S. 200.

${ }^{4}$ Diese vier Repräsentanten waren durch den Konventsbeschluß vom 9. April nach Straßburg entsandt worden. S. ihren Brief an das Comité de Salut public vom 18. April 1793 [Arch. Nat. Paris, AF II 247, doss. 2107, 42].

${ }^{5}$ AULARD, Recueil des actes du Comité de salut public, Bd. 3, S. 274; WERNER, L'approvisionnement, S. 200ff.

${ }^{6}$ Repr. Maribon-Montaut, Soubrany, Ruamps, Bericht an das Comité de Salut public vom 4. Mai 1793 [Arch. Nat. Paris, AF II 247, 2108, 8]. 
saß befindlichen Volksvertreter auf die von verschiedenen Verwaltungen des Départements erhobene Forderung, den Getreidepreis zu regulieren. Ihre Anordnung sah eine Erfassung sämtlicher Getreidevorräte vor. Sie verpflichtete Bauern und Händler, alles verfügbare Getreide auf die Märkte zu bringen und nur dort zu verkaufen; zusätzlich wurden Höchstpreise für die wichtigsten Kornsorten festgesetzt. Außerhalb der Märkte durften nur noch die Versorgungsoffiziere der Armee kaufen. Requisitionen für die Versorgung der Zivilbevölkerung wurden ausdrücklich erlaubt ${ }^{7}$.

Die Repräsentanten griffen mit diesen Anordnungen der nationalen Gesetzgebung vor. Zwar war der Konvent bereits im Februar von den Pariser Sektionen gedrängt worden, eine Preisbindung einzuführen, doch in Paris wurde erst am 4. Mai 1793 das Gesetz über das erste Maximum verabschiedet. Dieses bestätigte die im Elsaß getroffenen Entscheidungen: Jedes Département sollte entsprechend seinen wirtschaftlichen Gegebenheiten eigene Höchstpreise für Getreide festlegen. Darüber hinaus legalisierte der Konvent Hausdurchsuchungen bei Bauern und Bürgern, die im Verdacht standen, Getreide zurückzuhalten, und die Konfiskation von nicht deklariertem Getreide.

Das erste Maximum brachte keine Verbesserung der Lage; ebensowenig das am 13. Juni ausgesprochene Verbot, Assignaten in Bargeld umzutauschen oder das Gesetz vom 26. Juli, welches das Verstecken oder Horten von Nahrungsmitteln (accaparement) zum Verbrechen erklärte. Die vergleichsweise hohen Getreidepreise in den Nachbardépartements verschärften die Krise ${ }^{8}$.

Straßburgs Versorgung mit Nahrungsmitteln war seit dem Beginn des Sommers nicht mehr gewährleistet. Zunächst verbrauchte die Stadt die für den Belagerungsfall angelegten Vorräte. Außerordentliche Maßnahmen, besonders die am 28. Juli beschlossene allgemeine Getreiderequisition in allen Distrikten des Bas-Rhin, füllten von Zeit zu Zeit die Magazine. Auch die Erlaubnis des Konvents, die Rheinarmee aus allen umliegenden Départements zu versorgen, brachte Getreide nach Straßburg. Doch die großen Mengen, welche Bevölkerung und Garnison verbrauchten, konnten nicht aufgebracht werden ${ }^{9}$.

Am 5. August beschlossen die Repräsentanten Milhaud und Ruamps, das Getreidemaximum für das Elsaß aufzuheben. Sie mißachteten damit - ähnlich wie ihre Kollegen in den Départements Doubs, Nord, Charente, Haute-Vienne und Dordogne - die nationale Gesetzgebung. Ihr Wunsch, durch die Deregulierung die neue Ernte auf die Märkte und in die Magazine zu bringen, ging allerdings nicht in Erfüllung. Am 11. August verfügte Straßburg noch über Nahrungsmittel für acht Tage; am 22. August waren alle Vorräte aufgebraucht.

\footnotetext{
${ }^{7}$ Repr. Soubrany, Maribon-Montaut, Ruamps, Haussmann, Proclamation et Arrêté [...] concernant les subsistances, 1. Mai 1793 [Arch. Nat. Paris, AF II 245, doss. 2093, 5].

${ }^{8}$ WERNER, L'approvisionnement, S. 208.

${ }^{9}$ Ibid., S. $208 \mathrm{ff}$.
} 
Zur selben Zeit erreichten die Assignaten erneut einen Tiefstand ${ }^{10}$. Straßburg und seine Garnison lebten von der Hand in den Mund. Der Club tat das Seine zur Unterstützung der Behörden. Er sandte flammende Aufrufe an die Bauern und die affiliierten Gesellschaften des Umlands: Appréciez, frères et amis, l'importance de la nécessité d'approvisionner cette forteresse; abandonnons tout jusqu'à ce que nous ayons atteint à ce but ${ }^{11}$. Gleichzeitig wurde ein Komitee gegründet, das Geld für die Verteilung von Brot an Bedürftige beschaffen sollte $e^{12}$.

Auch die militärische Lage spitzte sich im Verlauf der ersten Hälfte des Jahres 1793 zu. Der Kriegseintritt Englands im Februar, die Niederlage in Belgien und der anschließende Verrat des Generals Dumouriez im März brachten Frankreichs Vormarsch im Norden zum Stehen. Mit dem Fall von Mainz im Juli 1793 brach die Ostfront. Die Niederlage Custines setzte das Elsaß einer massiven preußisch-österreichischen Gegenoffensive aus, welche über die Pfalz und Landau nach Südwesten zu rollen begann. Straßburg hatte als größte der drei Grenzfestungen des niederrheinischen Départements besondere Bedeutung im französischen Verteidigungskonzept. Daher wurde schon am 3. August, lange bevor Preußen und Österreicher tatsächlich vor den Toren standen, der Belagerungszustand über die Stadt verhängt. Wenige Tage später veranlaßten die Repräsentanten Lacoste und Guyardin zusätzliche Truppenaushebungen im Bas-Rhin und in dessen Nachbardépartements; mit den Rekruten sollte die Rheinarmee aufgestockt werden ${ }^{13}$.

In Paris setzten derweil die Sektionen den Konvent unter Druck, eine levée en masse zu organisieren. Die mobilisierten Massen sollten den Feind in einer kurzen, aber heftigen Attacke aus dem Land vertreiben. Robespierre lehnte eine solche Erhebung des Volkes ab; Danton gelang es jedoch, den Konvent zur Annahme des Projektes zu bewegen. Am 23. August 1793 verabschiedete das Comité de salut public eine Order, die vorsah, alle ledigen Männer zwischen 18 und 25 Jahren einzuberufen und in die republikanischen Truppen einzugliedern.

$\mathrm{Zu}$ dieser Zeit war im Bas-Rhin bereits eine massenhafte Mobilisierung im Gange - dies ist ein weiteres Beispiel für das Vorpreschen der Volksvertreter in den östlichen Départements. Seit August wurden die Freiwilligen zum Aufbruch an die Front aufgerufen. Die zuständigen Repräsentanten verkündeten: Peuple français, lève-toi tout entier! Prends l'attitude imposante du véritable souverain! Tous les despotes de l'Europe ont conjuré ta perte; c'est au moment

\footnotetext{
${ }^{10}$ WERNER, L'approvisionnement, S. $234 \mathrm{f}$.

11 La Société populaire de Strasbourg aux Sociétés affiliées de la République, Strasbourg o. D. [Bibl. Nat. Univ. Str., M 6809, 26].

${ }^{12}$ Les Citoyens réunis en Société populaire à leurs Concitoyens de la Commune de Strasbourg, Strasbourg o. D. [Bibl. Nat. Univ. Str., M 6809, 3].

${ }^{13}$ Repr. LACOSTE, GUYARDIN, Les Représentants du peuple [...] Aux citoyens de ces départemens, 6. Aug. 1793 [Arch. Nat. Paris, AF II 248, doss. 2113, 54].
} 
où tu viens de sanctionner la Constitution républicaine, qu'ils redoublent leurs efforts pour renverser l'édifice majestueux de ton bonheur ${ }^{14}$. Am selben Tag ordneten sie den Marsch der ersten Freiwilligenverbände an die Front $a^{15}$.

Als wenige Tage später der Erlaß des Wohlfahrtsauschusses im Elsaß publik gemacht wurde, verfaßte der Repräsentant Lacoste eine Instruction pour la levée en masse, in der er die Bürger aufforderte, ihre beste Kleidung anzuziehen, sich mit Verpflegung für zwei Wochen zu versehen, sich mit Gewehren, Hacken, Piken oder Ackergeräten zu bewaffnen und in kleinen Gruppen schnellstmöglich zur Front zu marschieren: Quand le peuple se lève en masse il n'y a aucun mouvement de régulier ${ }^{16}$. Einsatzort des Volkes unter Waffen sollte Weissenburg, der wichtigste Punkt der Front, sein ${ }^{17}$. Die Massenmobilisierung kam nur schleppend in Gang. Unausgebildete, schlecht ausgerüstete und mangelhaft versorgte Freiwilligentrupps schoben sich auf verschiedenen Wegen in Richtung Front. Daß die Freiwilligen häufig nicht ganz freiwillig kamen, zeigen Aufstände im Distrikt Barr. Um eine Ausweitung der Unruhen zu vermeiden, wurden harte Maßnahmen getroffen. Die Repräsentanten befahlen, que les maisons des rebelles soient rasées, et que les forêts où ils se seroient retranchés soient incendiées et qu'ils soient tous passés au fil de l'épée ${ }^{18}$.

Wenn es keine Versorgungskrise und keinen Krieg gegeben hätte, wären die Repräsentanten, die im Januar 1793 mit einer politischen Mission nach Straßburg geschickt wurden, bald wieder abgezogen worden. Da sich aber die Lage verschlechterte, folgte ihnen bis zum Sommer ein gutes Dutzend Kollegen nach; bis zum Ende der Terreur waren über dreißig Repräsentanten im Osten. Diese wurden später die Organisatoren des Terrors in der Provinz. Daraus könnte voreilig gefolgert werden, daß vor allem die widrigen Umstände die Terreur hervorbrachten. Der letzte Abschnitt hat jedoch gezeigt, daß es den Repräsentanten noch im Sommer 1793 gelang, für jedes Problem eine angemessene Lösung zu finden und auf die Verhältnismäßigkeit der Mittel zu achten. Obwohl die Krise schon bedrohlich war, setzten die Repräsentanten noch nicht den Schrecken als politisches Mittel ein. Verfolgt wurden nur wenige, denen Verstöße gegen Gesetze und Anordnungen nachgewiesen werden

${ }^{14}$ Repr. Milhaud, Ruamps, Borie, Proclamation des Représentants du peuple, 17. Aug. 1793 [Arch. Nat. Paris, AF II 248, doss. 2114, 8].

${ }^{15}$ Repr. Milhaud, RuampS, BoriE, Arrêté des Représentants du peuple, 17. Aug. 1793 [Arch. Nat. Paris AF II 248, doss. 2114, 12].

${ }^{16}$ Repr. LACOSTE, Instruction pour la levée en masse, o. D. [Arch. Nat. Paris AF II 249, doss. 2120, 42].

${ }^{17}$ Repr. LACOSTE, Milhaud, RuAMPS, BoriE, Général LANDREMONT: Lettre [...] aux administrateurs du Département des Vosges, 27. Aug. 1793 [Arch. Nat. Paris, AF II 248, doss. $2114,44]$.

${ }^{18}$ Repr. RUAMPS, Milhaud, Arrêté des Représentans du peuple près l'armée du Rhin, 24. Aug. 1793 [Arch. Nat. Paris, AF II 135, doss. 1046, 15]. 
konnten. Auch die lokale Autonomie war zwar beschnitten, aber nicht völlig außer Kraft gesetzt worden. Nach der Säuberung vom Januar 1793 arbeiteten die Volksvertreter noch mit den lokalen Autoritäten zusammen und nahmen deren Ansichten durchaus ernst. Dies zeigte sich beispielsweise bei der Einführung maximaler Getreidepreise, welche zunächst die örtlichen Verwaltungen gefordert hatten. Dies sind erste Hinweise darauf, daß Krieg, Versorgungskrise und Schreckensherrschaft nicht in einem einfachen Verhältnis von Ursache und Folge standen. Diese Hypothese wird im folgenden durch einen Vergleich zwischen den Entwicklungen des Sommers 1793 und des Winters 1793/94 überprüft.

Darüber hinaus ist deutlich geworden, daß die Repräsentanten im betrachteten Zeitraum keineswegs nur die Anordnungen der Zentrale umsetzten. Beim ersten Maximum folgte die nationale Vertretung Entscheidungen, die vorher in der Provinz gefallen waren; die Volksvertreter in den östlichen Départements scheuten sich wenige Monate später nicht, das Maximum außer Kraft zu setzen, als es ihnen nicht mehr erfolgversprechend schien. Auch die Massenmobilisierung hatte in Straßburg begonnen, bevor es eine nationale levée en masse gab. Die Repräsentanten waren in dieser Phase also eher eine zusätzliche lokale Autorität als das Werkzeug der Zentralgewalt.

\section{Das Ende der lokalen Autonomie}

Am 5. September 1793 setzte der Konvent den „Terror auf die Tagesordnung"; die Dekrete der folgenden Tage und Wochen konkretisierten diesen folgenschweren Beschluß: Am 9. September wurde die Pariser Revolutionsarmee ins Leben gerufen, deren wichtigstes Ziel es war, die Versorgung der Hauptstadt sicherzustellen ${ }^{19}$. Am 17. September wurde das Dekret gegen die „Verdächtigen“ verabschiedet, das an die bestehende Gesetzgebung gegen Emigranten, Fremde, Eidverweigerer und accapareurs anknüpfte ${ }^{20}$. Das Pariser Comité de sûreté générale und eine Vielzahl von Komitees in den Départements waren autorisiert, Denunziationen entgegenzunehmen, die „Verdächtigen" festnehmen und einem Revolutionsgericht vorführen zu lassen. Die Überwachung der Verdächtigen sollte durch die Einführung der cartes de civisme am 20. September erleichtert werden; diese Ausweise guten Bürgersinns sollten landesweit von Sektionsversammlungen und Komitees ausgestellt werden. Durch den Ausbau der Revolutionstribunale in Paris und den Départmenten sollte die flächendeckende Umsetzung des Verdächtigengesetzes

\footnotetext{
${ }^{19}$ Richard COBB, Les armées révolutionnaires, instrument de la Terreur dans les départements, 2 Bde., Paris 1961 u. 1963, hier: Bd.1, S. 225-306.

${ }^{20}$ Jean-Louis MATHARAN, Suspects et suspicion, 1792-1794, 3 Bde., Paris 1985.
} 
sichergestellt werden ${ }^{21}$. Am 29. September wurde mit dem großen Maximum, das sowohl die Preise für alle wichtigen Versorgungsgüter als auch die Löhne für ganz Frankreich bestimmte, eine staatliche Kontrolle der Wirtschaft durchgesetzt. Das Comité de salut public und das Comité de sûreté générale von Paris rückten jetzt ins Zentrum der Politik.

Die neuen Gesetze wurden in Straßburg umgesetzt, als am 13. Oktober 1793 die Front bei Weissenburg, $50 \mathrm{~km}$ nördlich von Straßburg, brach. Für die Preußen und Österreicher war der Weg nach Straßburg damit frei. Die Gefahr veranlaßte die im Osten befindlichen Volksrepräsentanten, mehr als bislang von ihren „unbegrenzten Vollmachten“ Gebrauch zu machen. Ihr Ziel war es nach wie vor, die Truppen aufzustocken, ihre Disziplin zu verbessern und die Versorgung von Armee und Bevölkerung zu gewährleisten; insofern gab es eine Kontinuität zum Sommer 1793. Die Mittel, welche die Volksvertreter einsetzten, um diese Ziele zu erreichen, änderten sich jedoch grundlegend: Einerseits machten sie die lokalen Autoritäten, die bislang Partner gewesen waren, zu ihrem Werkzeug, andererseits setzten sie auch den Schrecken auf die Tagesordnung. Wichtigstes Instrument zur Einschüchterung wurde die Guillotine. Beide Aspekte - die voll entwickelte lokale Diktatur der Volksvertreter und das System des Überwachens und Strafens - müssen getrennt behandelt werden, denn sie stehen für unterschiedliche Arten, mit Krieg und Krise umzugehen. Die Verkürzung der Befehlswege und die Durchführung von Zwangsrequisitionen läßt sich noch als rationale, vielleicht sogar angemessene Reaktion auf die drängenden Probleme interpretieren. Der Kampf gegen eine Verschwörung innerer Feinde, in dessen Verlauf die eigentlich zu verteidigende Bevölkerung angegriffen wurde, entbehrte jeglicher Logik. Beide Formen des Umgangs mit den äußeren Umständen werden in den folgenden Abschnitten dargestellt.

Bereits kurz vor dem Fall der Weissenburger Linie hatten die Volksrepräsentanten zu einem altbekannten Mittel gegriffen, um sich die Herrschaft über die wichtigste Stadt des Elsaß' zu sichern: Sie säuberten ein weiteres Mal die Verwaltungen. Am 3. Oktober 1793 suspendierten die Repräsentanten Guyardin und Milhaud einzelne feuillantinische Mitglieder des Conseil municipal, wodurch der ohnehin kleine Anteil an Stadtverwaltern, die nicht dem Club angehörten, weiter sank ${ }^{22}$. Nach dem Fall von Weissenburg mußte Straßburg jederzeit mit einem Angriff rechnen. Am 14. Oktober riefen die Kommissare Milhaud und Guyardin eine Versammlung der Verwaltungen ein, um Straßburg in ein Bollwerk gegen den Feind zu verwandeln. Um dieses Ziel zu erreichen, wurden verschiedene Anordnungen getroffen: Der Wald von Eckbols-

${ }^{21}$ Jean-Marc VARAUT, La Terreur judiciaire. La Révolution contre les droits de l'homme, Paris 1993, S. 135ff.

${ }^{22}$ Anordnung der Repr. GuYARDIN, MiLHAUD vom 3. Oktober 1793 [Arch. Dépt. Bas-Rhin, 6 L 44]. 
heim vor den Mauern von Straßburg sollte requiriert und aus strategischen Gründen abgeholzt werden. Gleichzeitig sollten Hausdurchsuchungen in Straßburg durchgeführt werden, um Vorräte aufzuspüren und accapareurs dingfest zu machen. Eine Kommission wurde gegründet, um alle Vorräte aus dem Umland in die Stadt zu bringen. Die Deportation der Eidverweigerer ins Landesinnere wurde angeordnet; auch Verdächtige aus dem Gefängnis im ehemaligen Séminaire sollten von nun an in sicherer Entfernung von der Grenze festgehalten werden. Die bouches inutiles sollten durch Ausweisungen so weit wie möglich reduziert, die Zahl der Arbeiter an den Befestigungsanlagen verdreifacht werden ${ }^{23}$.

Mit der Ankunft der Repräsentanten Saint-Just und Lebas in Straßburg am 2. Brumaire (23. Oktober 1793) schritt die Machtübernahme der Volksvertreter weiter fort. Das wichtigste Ziel ihrer Mission war es, die Rheinarmee aufzurütteln und auf eine Offensive vorzubereiten. Ihr Besuch in Straßburg galt vornehmlich den dort stationierten Truppen; gleichzeitig hielten sie es aber auch für nötig, im Rücken der Armee für Ordnung zu sorgen ${ }^{24}$. S'il est ici des traitres et des indifférents même à la cause du peuple, nous apportons le glaive qui doit les frapper ${ }^{25}$, hieß es in ihrer ersten Verlautbarung nach der Ankunft in Straßburg. Saint-Just und Lebas bezeichneten sich als envoyés extraordinaires. Sie ignorierten die Anwesenheit der anderen Représentants $d u$ peuple en mission, weil sie deren Vorgehensweise nicht für ausreichend streng hielten und legten dem Comité de salut public sogar nahe, sie abzuberufen $^{26}$. Daraufhin beschwerten sich die geschmähten Kollegen beim Wohlfahrtsausschuß: Cette qualité d'envoyés extraordinaires fait une mauvaise impression dans le public, et [...] elle semble annuller nos pouvoirs ou au moins les affaiblir dans l'opinion générale ${ }^{27}$. Saint-Just und Lebas ließen sich jedoch nicht beirren. Sie handelten weiterhin ohne Absprache mit ihren Kollegen, was zum einen dazu führte, daß ein weiteres übergeordnetes Befehlszentrum entstand, zum anderen bewirkte, daß unter den Volksvertretern eine Konkurrenz um die größere Härte im Kampf gegen die Feinde der Republik entstand. Vor allem aber verzichteten Saint-Just und Lebas darauf, sich mit den örtlichen Verwaltungen abzusprechen. Ihre Anordnungen beruhten nicht auf Beschlüssen von Gremien, sondern lediglich auf ihren eigenen Ent-

\footnotetext{
${ }^{23}$ BETZINGER, Vie et mort d'Euloge Schneider, S. 262.

${ }^{24}$ Jörg MONAR, Saint-Just. Sohn, Denker und Protagonist der Revolution, Bonn 1993, S. 447f.

${ }^{25}$ Les représentants du peuple envoyés extraordinairement à l'armée du Rhin, aux soldats de cette armée, 3 brum. II, in: SAINT-JUST, Euvres complètes, Paris 1984, S. 543.

${ }^{26}$ Repr. SAINT-JUST, LEBAS, Les représentants à l'armée du Rhin au Comité de salut public, 3 brum. II, in: Ibid. S. 544.

${ }^{27}$ Repr. MALLARME, LACOSTE, GUYARDIN, Brief an das Comité de salut public, 6 brum. II [Arch. Nat. Paris, AF II 248, doss. 2116, Nr. 8].
} 
scheidungen. Den lokalen Autoritäten blieb nur noch, ihre Beschlüsse schnell, genau und ohne Rückfragen in die Tat umzusetzen.

Mit der am 10. Brumaire (31. Oktober 1793) von Saint-Just und Lebas angeordneten Anleihe von neun Millionen livres bei den „Reichen“ der Stadt begann eine Serie von außerordentlichen Requisitionen der Repräsentanten bei den Straßburgern ${ }^{28}$. Wenig später wurden von den „Reichen“ Betten für verletzte Soldaten eingetrieben ${ }^{29}$, dann Mäntel $^{30}$, später Weine ${ }^{31}$, am 25. Brumaire (15. November 1793) 10.000 Paar Schuhe ${ }^{32}$ und schließlich, am Ende des Monats Brumaire, alle verfügbaren Kupfer- und Bleigegenstände ${ }^{33}$. Die beschlagnahmten Güter und die freiwilligen Spenden der Straßburger wurden direkt an die Armeen geliefert oder in Magazinen eingelagert.

Am 12. Brumaire (2. November 1793) griffen Saint-Just und Lebas erneut in die Selbstverwaltung Straßburgs ein. Wie ihre Vorgänger versuchten sie, die Verwaltungen mit Männern zu besetzen, die ihnen ergeben waren. Sie säuberten Départements-, Distrikts- und Munizipalrat; die Volksgesellschaft wurde beauftragt, aus ihren Reihen eine provisorische Stadtverwaltung zu bilden. Die abgesetzten Verwalter sollten nach Châlons-sur-Marne gebracht werden ${ }^{34}$. Diesmal protestierte sogar der Jakobinerclub, da viele seiner Mitglieder betroffen waren. Saint-Just und Lebas wiesen diese Kritik jedoch zurück: Vous êtes indulgents pour des magistrats qui n'ont rien fait pour la patrie ${ }^{35}$. Die wenig später gebildete städtische Verwaltung enthielt einen noch größeren Anteil von Jakobinern als ihre Vorgängerin: Drei Viertel der Mitglieder des Conseil général de la Commune gehörten dem Club an. Ein einziger der eingesetzten Stadtverwalter hatte 1792 der Auditoire-Gesellschaft angehört ${ }^{36}$. Der Bürgermeister Monet war von der Säuberung nicht betroffen. Sein Verhältnis zu den

${ }^{28}$ Repr. SAINT-JUST, LEBAS, Arrêté, 12 brum. II, in: Livre bleu, Pièces à l'appui Nr. 11, Bd. 1, S. 9f.

${ }^{29}$ Repr. SAINT-JUST, LEBAS, Arrêté, 24 brum II, in: Livre bleu, Pièces à l'appui Nr. 29, Bd. 1, S. 19.

${ }^{30}$ Repr. SAINT-Just, LEBaS, Proclamation, 25 brum II, in: Livre bleu, Pièces à l'appui Nr. 30, Bd. 1, S. 19.

${ }^{31}$ Repr. SAINT-JuSt, LEBAS, Arrêté, 28 brum II, in: Livre bleu, Pièces à l'appui Nr. 33, Bd. 1, S. 24f.

${ }^{32}$ Repr. SAINT-JUST, LEBAS, Brief an die Municipalité vom 24 brum II, in: Livre bleu, Pièces à l'appui Nr. 26, Bd. 1, S. 18.

${ }^{33}$ Repr. LEMANE, BAUDOT, Arrêté, 30 brum II, in: Livre bleu, Pièces à l'appui Nr. 35, Bd. 1, S. $27 \mathrm{f}$.

${ }^{34}$ Repr. SAINT-JUST, LEBAS, Arrêté, 12 brum II (und Zusatz Lebas vom 13 brum II), in: Livre bleu, Pièces à l'appui Nr. 13 u. 14, Bd. 1, S. $11 \mathrm{f} \mathrm{u.} 13$.

${ }^{35}$ Repr. SAINT-JUST, LEBAS, Réponse à la Société populaire de Strasbourg, 24. brum. II, in: SAINT-JUST, Euvres complètes, S. 627.

${ }^{36}$ Diese Angaben wurden durch den Vergleich zwischen der im Kapitel II.2 vorgestellten Datenbank und den Listen der Munizipalitäten Straßburgs ermittelt, die Claude Betzinger (Straßburg) freundlicherweise zur Verfügung gestellt hat. (Lt. Arch. Mun. Str., Documentation du Conseil mun. 91/879). 
Repräsentanten war, wie im folgenden noch gezeigt werden wird, besonders gut.

Der Club hatte auch sonst eine Schlüsselrolle bei der Besetzung von vakanten und neu geschaffenen Posten; ihn erreichten immer wieder Schreiben, in denen um Listen mit fähigen und linientreuen Verwaltern gebeten wurde ${ }^{37}$. So wurde nach Kandidaten für die Besetzung von Geschworenengerichten gefragt: Ils doivent se trouver dans votre sein, où l'amour de la patrie et les vertues rassemblent les plus chauds patriotes ${ }^{38}$. Auch die Distriktsverwaltung wandte sich an den Club: Nous vous prions donc citoyens de [...] nous envoyer dans le plus court délai possible l'état nominatif des citoiens qui vous sont connus pour réunir aux sentimens civiques révolutionnaires les vertus et talens nécessaires pour occuper les différentes places du gouvernement ${ }^{39}$. Der Triumph der Jakobiner war vollendet, als auf ihr Betreiben die Präsidenten und Sekretäre der Sektionen verhaftet wurden ${ }^{40}$; das Verbot der Permanenz der Sektionen ließ diese Institution endgültig an Einfluß verlieren ${ }^{41}$. Dies bedeutete auch das Ende des Einflusses der Gemäßigten.

Auch Saint-Just und Lebas rechtfertigten ihr Vorgehen mit den ,äußeren Umständen“, aus der drohenden Gefahr leiteten sie jedoch, anders als ihre Vorgänger, die Notwendigkeit zur vollständigen Abschaffung der lokalen Autonomie und Selbstverwaltung ab. Die Machtübernahme der Volksrepräsentanten in der Zeit der Terreur gehorchte dennoch der gleichen Logik wie die Eingriffe des Zentrums im Frühjahr und Sommer 1793. Da die Bedrohung stärker wurde, waren tiefgreifendere Einschränkungen der lokalen Autoritäten und größere Opfer der Bevölkerung zu rechtfertigen. War also die Politik der Terreur nur eine Fortsetzung der Eingriffe des Sommers 1793 mit anderen Mitteln? Die Analyse der ,äußeren Umstände“, der Mittel gegen die Krise und der städtischen Machtstrukturen scheint nahezulegen, daß die Kontinuitäten vom Sommer zum Herbst überwogen. In den folgenden Abschnitten wird sich jedoch zeigen, inwiefern der Beginn der Terreur einen Bruch bedeutete.

\footnotetext{
${ }^{37}$ Brief der Distriktsverwaltung an den Club, 11. niv. II [Arch. Mun. Str., Fonds 5/15, 156].

${ }^{38}$ Brief des Substitut de l'agent national de la Commune an den Club, 21 priarial II [Arch. Mun. Str., Fonds 5/15, 300].

${ }^{39}$ Brief der Distriktsverwaltung an den Club, 23. Nov. 1793 [Arch. Mun. Str., Fonds 4/11, 224].

${ }^{40}$ Repr. SAINT-JUST, LEBAS, Brief an die Munizipalität, 16 brum. II, in: Livre Bleu, Pièces à l'appui Nr. 19, Bd. 1, S. 15.

${ }^{41}$ Clubprotokoll vom 28 brum. II, in: Livre Bleu, Bd. 2, S. 313; La société populaire de Strasbourg aux Représentants du peuple près les armées du Rhin et de la Moselle, 2 frim. II, in: Livre Bleu, Nr. 101, Bd. 2, S. 204f. Abschaffung der Permanenz der Sektionen: Repr. LEMANE, BAUDOT, Copie de l'arrêté des Représentans du peuple près l'armée du Rhin et de la Moselle, 4 frim II [Arch. Nat. Paris, AF II 135, doss. 1038, 45].
} 
Verschwörungsangst und Bestrafungswille

Der Beginn der Terreur führte in Straßburg nicht nur zur Abschaffung der lokalen Autonomie, sondern auch zur zunehmenden Verbreitung von Angst und Schrecken. Es waren vor allem die Maßnahmen zur Überwachung und Bestrafung der „Feinde der Republik“, welche einen neuen Abschnitt der Revolutionsgeschichte einleiteten. Voraussetzung dafür war ein gewandeltes jakobinisches Selbstverständnis, das mehr als je von kollektiven Ängsten geprägt war. Die wichtigste Ursache der Angst war das Näherrücken der Front. Doch nur weil die jakobinische Führung von Straßburg fürchtete, der äußere Feind könne im Inneren Verbündete haben, kam es zur Repression gegen französische Bürger. Nur weil Krieg und innere Krise als Werk einer Verschwörung gedeutet wurden, entstand die Politik der Terreur. Im folgenden werden die Deutungsmuster analysiert, durch die äußere Bedrohung und innere Repression verknüpft wurden ${ }^{42}$.

Ende Oktober 1793 wurde den Représentants du peuple ein besorgniserregender Brief zugespielt, der angeblich von einem emigrierten Adligen namens Saint-Hilaire verfaßt und an einen Freund in Straßburg gerichtet war. SaintHilaire berichtete darin von einem detaillierten Plan, mit dessen Hilfe die Eroberung Straßburgs möglich gemacht werden sollte: Strasbourg est à nous; dans trois jours au plus tard, j'espère vous y embrasser, schrieb Saint-Hilaire. Der Straßburger Freund und andere in der Stadt befindliche Verschwörer sollten die Jakobiner ablenken: Ces maudits Jacobins veillent, tenez les en halleine; faites leur faire des bévues tant que vous pourrez, ils se fient à vous, moyen de plus pour les tromper. Zu einer verabredeten Stunde sollten dann zweitausend als Nationalgarden verkleidete émigrés vor der Pforte von Straßburg stehen, die ihnen von innen geöffnet würde:

C'est tout ce-que nous avons de meilleur, c'est l'élite de la noblesse Françoise. [...] Deux cents d'entre eux se porteront chez les commissaires de la Convention et les égorgeront sans coup férir ainsi que tous leurs suppôts. Tous vos honnêtes gens n'auront pour cri de ralliement que le nom du roi et une cocarde blanche, seul signe qui sera respecté. Les municipaux dont nous avons les noms, seront poignardés; les autres, nos amis, seront respectés. Ils mettront leur écharpe blanche sur le champ.

Nach dem Eindringen der Verschwörer in die Stadt sollte an verschiedenen Stellen gleichzeitig Feuer gelegt werden. Bei dem Handstreich könne man auf

${ }^{42}$ Zur Verschwörungsangst: Timothy TACKETT, Conspiracy Obsession in a Time of Revolution. French Elites and the Origins of the Terror, 1789-1792, in: AHR 105,3 (2000) S. 691713. 
die Unterstützung eines grand nombre de nos prêtres zählen; notre bon ami Pitt habe das Unternehmen finanziert ${ }^{43}$.

Die heftigen Reaktionen auf diesen Brief zeigen, welch zentrale Rolle Verschwörungsängste inzwischen im politischen Denken spielten. Ein Bericht in der Straßburgischen Zeitung, die allerdings nicht mehr die Stimme der GemäBigten war, vermutete, daß wahrscheinlich sehr viele Schuldige selbst in unserer Stadt als Ausführer dieses abscheulichen Plans angestellt waren ${ }^{44}$. Als Mittel gegen die angeblichen Verschwörer wurden Wachsamkeit und das Schwert der Gerechtigkeit ${ }^{45}$ empfohlen. Die Repräsentanten Milhaud und Guyardin ordneten nächtliche Hausdurchsuchungen, eine verstärkte Suche nach Verdächtigen und l'arrestation de tous les riches égoistes et contre-révolutionnaires qui pouvoient être en relation avec l'étranger ${ }^{46}$ an. Auch die von Saint-Just und Lebas vorgenommene Säuberung der Munizipalität wurde mit der Aufdeckung der Verschwörung ${ }^{47}$ von Saint-Hilaire gerechtfertigt.

Es war nicht das erste Mal, daß Straßburg sich von einer Verschwörung bedroht glaubte. Bereits im Umfeld der Zivilverfassung des Klerus hatten die Clubbisten ihre Gegner als Verschwörer bezeichnet. Auch die Flucht des Königs wurde als Konspiration gegen die Revolution interpretiert; schon damals hatte man Maßnahmen gegen die mauvais citoyens ins Auge gefaßt. Im Sommer 1792 hatten die Jakobiner die Gemäßigten als Teil einer Verschwörung angesehen, in welche die deutschen Fürsten, die Adelsemigration, die Eidverweigerer und der Hof verwickelt seien. Die Varennes-Krise war jedoch nach wenigen Tagen überstanden; die Vorwürfe der Jakobiner von 1792 richteten sich gegen eine überschaubare Gruppe öffentlicher Personen. In beiden Fällen handelte es sich also um Verschwörungen, die begrenzt und deshalb kontrollierbar erschienen. Krieg und Versorgungskrise hingegen dauerten monatelang an. Die jakobinische Führung von Straßburg fürchtete daher, ein großer Kreis von Personen, ja vielleicht sogar die Mehrheit der Bevölkerung sei an der Verschwörung beteiligt. Die bis zum Anfang des Jahres 1793 noch präsente Vorstellung, die Elsässer seien ein bon peuple, wurde daher aufgegeben. Es war diese Ausweitung der Verschwörungstheorie, die zuvor nur ein unbedeutender Bestandteil der jakobinischen Ideologie gewesen war, zum wichtigsten Deu-

${ }^{43}$ Copie de la lettre adressée à Monsieur le citoyen en c. D. 17.18 place d'armes à Strasbourg, et envoyée aux Représentans du peuple par le général Michaud, in: Livre Bleu, Pièces à l'appui Nr. 87, Bd. 1, S. 130 f.

${ }^{44}$ Art. „Strasburg den 14ten Brumere (4ten Nov.)“, in: Straßburgische Zeitung, Nr. 260, 5. Nov. 1793.

${ }^{45}$ Ibid.

${ }^{46}$ Proclamation des citoyens J. B. MILHAUD et GUYARDIN, représentans du peuple près l'armée du Rhin; Aux habitans, à la garnison de Strasbourg et à l'armée du Rhin. 11 brum. II [Arch. Nat. Paris, AF II 248, doss. 2116, Nr. 23].

${ }^{47}$ Repr. SAINT-JUST, LeBaS, Arrêté, 24 brum. II, Livre Bleu, Pièces à l'appui Nr. 13 u. 14, Bd. 1, S. 11f. 
tungsmuster, welche die Terreur prägte und ihren Beginn zu einem tiefen Einschnitt machte.

Die Ausbreitung der Phobie vor Verschwörungen brachte einen weiteren Wandel der Feindbilder und des Selbstverständnisses mit sich. Statt des konkreten Feindes hatte man jetzt einen Gegner, der gleichzeitig bedrohlicher und diffuser war. Verschwörer waren nicht nur diejenigen, die im Geheimen einen Plan zum Sturz der Republik schmiedeten, sondern auch all jene, die nicht ideologisch konform oder nicht kooperationsbereit waren. Die Feuillants oder Modérés gehörten deshalb genauso zur Verschwörung wie accapareurs oder Assignatenbetrüger. Reichtum, der nicht zum Wohl der Republik eingesetzt wurde, galt als Indiz für verschwörerische Absichten. Der Intrige verdächtig waren ehemalige Adlige, Fremde und Emigranten und all jene, die mit ihnen verkehrten. Das Bild der Verschwörung hatte schließlich auch eine religiöse und eine sprachliche Dimension; diese werden in den folgenden Kapiteln behandelt.

Die Jakobiner richteten ihren Blick also voller Mißtrauen auf ein Volk, das nicht mehr wie zum Anfang der Revolution Gemeinschaft und Familie, sondern eine schwer durchschaubare Masse war, in welcher sich maskierte Feinde verbargen ${ }^{48}$. Weil das integrative Einheitskonzept, von dem die frühen Jakobiner ausgingen, der neuen Sicht nicht mehr angemessen war, konzentrierte man sich jetzt auf die Herstellung von innerer Einheit in einem immer kleiner werdenden Zirkel. Nicht Integration und Offenheit, sondern Exklusion und Geschlossenheit wurden zu den bestimmenden Merkmalen des radikalen Jakobinismus. Wer gehörte noch zum inneren Zirkel? Die Jakobiner rechneten grundsätzlich all diejenigen zu den ihren, die bereit waren, mit aller Kraft und der nötigen Härte gegen die Verschwörung zu kämpfen. Die Vorstellungen davon, wie mit den Verschwörern verfahren werden soll, wurden deshalb zu einem integralen Bestandteil der Selbstdefinition.

Die Bedrohlichkeit der Verschwörung legte es nahe, harte Gegenmittel zu wählen. Die Jakobiner waren bereit, jeden einzelnen zu prüfen, alle Verdächtigen zu internieren und alle Schuldigen zu eliminieren. In einem Brief des Wohlfahrsausschusses an den Straßburger Club hieß es:

Vous serez nos plus puissants auxiliaires. Le dernier fil des conspirations sera rompu: nous balayerons les restes impurs du fédéralisme, qui infeste encore une grande partie des administrations. Dévoiler l'intrigue, qui a souillé les fonctions publiques; arracher le masque aux tartuffes du patriotisme; à la superstition son poignard et ses torches; suivre dans le labyrinthe de leurs manæuvres tortueuses les agents, les complices, les émissaires des tyrans; écraser les dernièrs têtes de la trahison, dont l'hydre cherche à ranimer ses tronçons épars et divisés; dénoncer, et l'agent infidèle ou pré-

${ }^{48}$ WAHNICH, L'impossible citoyen, S. $27 \mathrm{ff}$. 
varicateur, et le lâche déserteur de son poste, et l'être corrompu qui vend sa pensée et trafique de sa conscience, et l'égoïste qui n'a point de patrie; porter enfin, sur tous les hommes publics, ce flambeau qui entre vos mains projette une lumière immense, et à la lueur duquel tous les coupables pâlissent $^{49}$.

Die Beispiele dafür, daß sich die Jakobiner zunehmend über ihre Bereitschaft zur Gewalt gegen einen diffusen Feind definierten, sind zahlreich. Der Volksrepräsentant Baudot rief in einer Ansprache im Club auf, gegen „Egoisten“, „Feiglinge" und „Feinde des Volkes“ vorzugehen: Détruisons-les donc entièrement. Faisons-les disparaitre d'un sol qu'ils ont souillé; fussent-ils un million, ne sacrifierait-on pas la vingt-quatrième partie de soi-même, pour détruire une gangrène, qui pourrait infecter tout le reste du corps ${ }^{50}$. Bei einer Festveranstaltung verkündete der Jakobiner Boy feierlich, er wolle lieber 10.000 Aristokraten guillotinieren als einen tugendhaften Republikaner opfern: Nous serions aussi coupables que nos ennemis, que les ennemis de la patrie, si nous étions assez lâches pour leur pardonner ${ }^{51}$. Im Zusammenhang mit der Forderung nach einem außerordentlichen Gerichtshof erinnerte der Clubpräsident Alexander an die Gewalt, die im Ancien Régime Gewalt gegen innere Feinde eingesetzt wurde, um so Gegengewalt zu legitimieren:

Hérode ne fit-il pas [...] massacrer tous les enfants qui étaient dans ses états? L'église faible dans ses commencements, ne devint elle pas persécutrice, quand elle fut plus forte? Vous connaissez l'histoire de Constantin, le massacre des Albigois; combien de sang l'ambition des rois de Portugal et d'Espagne n'a-t-elle pas coûté aux peuples du nouveau monde? Vous parlera-t-on des milliers d'infortunés que l'inquisition fait périr au nom d'un Dieu de bonté; la révocation de l'édit de Nantes de cet infame Louis XIV et sa bégueule de maîtresse n'a-t-elle pas enlevé par le fer, les prisons, l'exportation, 150.000 familles? Qu'ils parlent après ces exemples, les tyrans. Cette mesure d'exterminer les gens suspets est nécessaire, vigoureuse, atterre les malveillants et forcera tous les traitres à rentrer dans la poussière; quel sera le mode pour hater son exécution? Il est possible que des patriotes se trouvent confondus avec ces misérables; il faut savoir les distinguer ${ }^{52}$.

Bei einer Debatte über die Verdächtigen wurde im Club gefordert que les modérés, les feuillants, les égoïstes et tous les ennemis de la patrie tombent sous

${ }^{49}$ Adresse des Comité du Salut public an die Soc. pop. vom 16. pluv. II, in: HEITZ, Les sociétés politiques, S. 328 .

${ }^{50}$ Ansprache des Repr. BAUdot im Club, 9. Dez. 1793, in: HEITZ, Les sociétés politiques, S. 305 .

${ }^{51}$ Discours pronconcé dans le Temple de la Raison de Strasbourg par le citoyen BoY, 30 pluv. II, Strasbourg 1794, S. 14 [Bibl. Nat. Univ. Str., M 5514].

${ }^{52}$ Clubprotokoll vom 13. Dez. 1793, in: HEITZ, Les sociétés politiques, S. 308. 
le glaive de la $l o i^{53}$. Die zitierten Aussagen mögen genügen, um den Proze der Abkapselung einer immer kleineren Führungsschicht, die Ausgrenzung der großen Masse als potentielle „Verschwörer" und den Wille zur Bestrafung, ja Vernichtung derselben zu illustrieren.

Ähnlich wie die Verschwörungstheorien war auch der Wille zur Bestrafung nicht erst seit dem Beginn des Terrors im Club vorhanden; unerbittliche Gewalt gegen Gegner war schon in den Auseinandersetzungen des Jahres 1792 gefordert worden. Im Frühjahr und Sommer hatte Eulogius Schneider die Notwendigkeit einer harten politischen Justiz gegen Rebellen und Gemäßigte gefordert. Die Gewaltbereitschaft war also kein neues Element im jakobinischen Konzept von Politik; allerdings war die Gruppe derer, die Gewalt anwendeten, gewachsen; Ansichten, die vorher nur die exaltiertesten Straßburger Jakobiner vertreten hatten, wurden zu allgemeinem Gedankengut. Das Spektrum der den politisch Aktiven zur Verfügung stehenden gewalttätigen Mittel hatte sich erweitert. Gleichzeitig war das Feindbild des Jakobinismus diffus geworden, was ein rasches Anwachsen der Opferzahlen mit sich brachte. Ob die Jakobiner strategisch handelten und die drohende Gefahr überzeichneten, um so härtere Mittel zu rechtfertigen, läßt sich mithilfe der hier ausgewerteten Quellen nicht ermitteln. Unklar bleibt des weiteren, ob vor allem die Volksvertreter oder die lokalen Clubbisten die Verschwörungsängste in Straßburg schürten; in den ersten Monaten der Terreur sprach die gesamte Führung die gleiche Sprache.

\section{Überwachen und Strafen}

Das neue jakobinische Selbstverständnis war die Grundlage für die Entstehung neuer Institutionen in Straßburg, deren Aufgabe darin bestand, die Feinde des Jakobinismus aufzuspüren und zu vertilgen. Am 8. Oktober 1793 richteten die Représentants du peuple Guyardin und Milhaud ein Comité de surveillance et de sûreté générale ein, das mit Mitgliedern des Clubs besetzt wurde ${ }^{54}$. Seine Aufgabe war es, Denunziationen entgegenzunehmen, Listen von Verdächtigen zu erstellen sowie Verhaftungen und Deportationen anzuordnen. $\mathrm{Zu}$ den ersten Aktionen, welche das Komitee in Angriff nahm, gehörte die Deportation einiger alter Gegner aus dem Lager der Gemäßigten, unter ihnen die im Januar abgesetzten Verwalter Treuttel und Wangen ${ }^{55}$.

\footnotetext{
${ }^{53}$ Clubprotokoll vom 14. Dez. 1793, in: HEITZ, Les sociétés politiques, S. 309.

${ }^{54}$ Repr. GuYardin, Milhaud, Arrêté, 17 vend. II [Arch. Nat. Paris, AF II 135, doss. 1044, 23].

${ }^{55}$ Procès-verbal du Comité de surveillance et de sureté générale, 23 vend. II, in: Livre Bleu, Procès-verbaux du Comité de surveillance, Bd. 1, S. 6f. Listen mit Urteilen des Komitees [Arch. Nat. Paris, AF II 135, doss. 1041, Nr. 1 u. 2].
} 
Das Comité de surveillance entschied Tag für Tag über das Schicksal einiger Dutzend Menschen, und es arbeitete eng mit Polizei, Nationalgarde und Armee zusammen, welche die angeordneten Verhaftungen durchführten ${ }^{56}$. Es hatte nicht das Recht zu verurteilen; dafür war zunächst noch das Kriminalgericht zuständig ${ }^{57}$. Da dieses nicht zügig arbeitete, waren die Gefängnisse bald überfüllt. Das Komitee war nicht die einzige Institution, welche Verhaftungen in Auftrag gab oder vornahm. Die Stadtverwaltung war dazu ebenso autorisiert wie die militärischen Autoritäten und die Représentants du peuple. Um der Überfüllung der Gefängnisse entgegenzuwirken, regte das Komitee an, eine Kommission zu gründen, welche die Verdächtigen nach einem vereinfachten Verfahren aburteilen sollte ${ }^{58}$. Bereits am 14. Oktober 1793 wurde das neugegründete Komitee angewiesen, alle internierten Eidverweigerer und Verdächtigen ins Landesinnere zu deportieren ${ }^{59}$.

Saint-Just und Lebas forderten gleich nach ihrer Ankunft eine Liste aller Verdächtigen an, welche ihnen das Comité de surveillance umgehend lieferte $^{60}$. Noch am selben Tag beauftragten sie das Komitee, mit der Verhaftung der aufgelisteten Verdächtigen zu beginnen ${ }^{61}$. Es folgten weitere Säuberungen; sie betrafen zunächst die Nationalgarde, deren gesamter Generalstab verhaftet und nach Dijon gebracht wurde ${ }^{62}$. Die Repräsentanten Milhaud und Guyardin ließen derweil Bankiers, Geldwechsler, Notare und andere Personen internieren, welche verdächtigt wurden, in Kontakt mit dem Feind zu stehen. Der Besitz der für schuldig Befundenen wurde eingezogen ${ }^{63}$. Die Einführung der cartes civiques in Straßburg trug dazu bei, daß ein immer größerer Teil der Bevölkerung die Macht des jakobinischen Staates zu spüren bekam. Jeder Bürger war gehalten, sich beim Comité de surveillance einen solchen $\mathrm{Pa} ß$ zum Beweis seines tadellosen Verhaltens ausstellen zu lassen. Wer nicht über eine Carte civique verfügte, wurde zur Gruppe der Verdächtigen gezählt ${ }^{64}$.

\footnotetext{
${ }^{56}$ Ibid. S. 10.

${ }^{57}$ Protokolle des Tribunal criminel révolutionnaire [Arch. Dépt. Bas-Rhin, 129 L 1].

${ }^{58}$ Procès-verbal du Comité de surveillance et de sureté générale, 5. niv. II, in: Livre Bleu, Procès-verbaux du Comité de surveillance, Bd. 1, S. $74 f$.

${ }^{59}$ Repr. Milhaud, GuYardin, Les Représentants du peuple au comité de surveillance, 23 vend. II, in: Livre Bleu, Pièces à l'appui Nr. 4, Bd. 1, S. 6.

${ }^{60}$ Repr. SAINT-JUST, LeBAS, Proclamation vom 9 brum. II, in: Livre Bleu, Pièces à l'appui Nr. 9, Bd. 1, S. 8f.; Procès-verbal du Comité de surveillance et de sureté générale, 12. brum. II, in: Livre Bleu, Procès-verbaux du Comité de surveillance, Bd. 1, S. 12f.

${ }^{61}$ Repr. SAINT-JuST, LEBAS, Arrêté, 9 brum. II, in: Livre Bleu, Pièces à l'appui Nr. 8, Bd. 1, S. 8.

${ }^{62}$ Repr. Milhaud, Guyardin, Arrêté, 14. Brum. II, in: Livre Bleu, Pièces à l'appui Nr. 15, Bd. 1, S. 13.

${ }^{63}$ Repr. GUYARDIN, Milhaud, Arrêté, 9 brum. und 18 brum. II, in: Livre Bleu: Pièces à l'appui Nr. 10 u. 24, Bd. 1, S. 9 u. 17.

${ }^{64}$ Anordnung des Stadtkommandanten Dièche vom 12 brum. II, in: Livre bleu, Pièces à l'appui Nr. 12, Bd. 1, S. 10f. Dazu: Art. „Straßburg“, in: Straßburgische Zeitung Nr. 270, 26 brum. II.
} 
Kurz nach dem lokalen Überwachungsausschuß wurde diejenige Institution ins Leben gerufen, welche am meisten zur Verbreitung des Schreckens in dieser ersten Phase der Revolution beitrug. Eine gemeinsame Anordnung mehrerer Volksrepräsentanten regelte die Einrichtung einer armée révolutionnaire, wie es sie in Paris und vielen anderen Départements längst gab ${ }^{65}$. Der Straßburger Revolutionsarmee wurde ein mobiler Gerichtshof (Commission civile près l'armée révolutionnaire) zur Seite gestellt, welcher Widerstände gegen die Requisitionen von Versorgungsgütern für die Armee brechen sollte. Die Revolutionsarmee und ihre Kommission sollten mit äußerster Härte vorgehen: Une triste expérience ne nous apprend que trop que le moment est arrivé, d'agir, de frapper, d'exterminer, dans quelques endroits qu'ils se trouvent, tous citoyens sourds aux besoins de la patrie, tout citoyen rebelle à la loi ${ }^{66}$. Um dieses Programm umzusetzen, wurde die Kommission ermächtigt, all diejenigen in einem Kurzverfahren abzuurteilen, welche die Versorgung der Truppen behinderten.

Die Revolutionsarmee des niederrheinischen Départements wurde nie umfassend organisiert; nur zwei détachements wurden behelfsmäßig aufgestellt. Die Kommission hingegen nahm mit großer Energie ihre Arbeit auf. Das Tribunal entwickelte sich zum Inbegriff der revolutionären und außerordentlichen Justiz im Bas-Rhin. Dies lag nicht zuletzt daran, daß dieses Tribunal von Eulogius Schneider dominiert wurde, der nicht nur an die Notwendigkeit einer revolutionären Justiz glaubte, sondern sich auch durch besonders hartes Durchgreifen bei den Repräsentanten beliebt machen, diese vielleicht sogar übertrumpfen wollte. Die Kommission reiste durch die elsässischen Dörfer und Städte. Schneider ließ in drei Wochen über 300 Personen vorführen, denen politische oder wirtschaftliche Verfehlungen vorgeworfen wurden. Der größte Teil von ihnen wurde zu Geld- und Freiheitsstrafen verurteilt. Die Kommission der Revolutionsarmee fällte 33 Todesurteile. Die Mitglieder der Kommission waren an keine vorgegebene Prozedur gebunden und sie waren keine Rechenschaft schuldig ${ }^{67}$. Als Herren über Leben und Tod fühlten sie sich den gewöhnlichen Bürgern überlegen, was sich in ihrem täglichen Verhalten auch außerhalb der Kommission zeigte. Der Richter Clavel wurde beispielsweise nach dem Ende der Terreur angeklagt, weil er durch die Straßen von Straßburg geritten sei und willkürlich Strafgelder von Passanten für seine private Kasse eingetrieben habe ${ }^{68}$. Die wichtige Frage, wie es möglich war, daß eine Institution in so eklatanter Weise die ihr zugesprochenen Kompeten-

${ }^{65}$ Zum Vergleich: CoBB, Les armées révolutionnaires, Bd. 1, S. $299 \mathrm{ff}$.

${ }^{66}$ Armée révolutionnaire. Au nom de la république française, 24 vend. II [Arch. Nat. Paris, AF II 245, doss. 2093, 10].

${ }^{67} \mathrm{Vgl}$. BETZINGER, Vie et mort d'Euloge Schneider, S. $245 \mathrm{f}$.

${ }^{68}$ Tribunal révolutionnaire à Strasbourg; dossier des juges Clavel, Schneider et Taffin [Arch.

Dépt. Bas-Rhin, 1 L 1534]. 
zen überschreiten konnte, ohne sofort abberufen zu werden, ist nach dem heutigen Kenntnisstand nicht zu beantworten ${ }^{69}$.

Mit den Siegen an der Ostfront, mit dem Beschluß über die Einrichtung eines Gouvernement révolutionnaire (Gesetz vom 14. Frimaire) und vor allem mit der Abreise Saint-Justs und Lebas' entstand eine Atempause. Die zurückgebliebenen Repräsentanten lösten die außerordentlichen Institutionen der Terreur sukzessive auf. Zunächst wurden die Revolutionsarmee und ihre Kommission abgeschafft. Die revolutionäre Justiz sollte in die Hände der regulären Tribunale gelegt werden. Dazu stockte man das Kriminalgericht auf und erklärte es zum Revolutionsgericht ${ }^{70}$. Am 5. Nivose des Jahres II (25. Dezember 1793) wurde das erste Comité de surveillance geschlossen. Durch diese Maßnahmen wurde der Terror jedoch nicht weniger rigide und unbarmherzig. An die Stelle des blutigen Enthusiasmus trat eine kalte Bürokratie des Todes, welche den Schrecken professioneller und routinierter fortsetzte. Die Mechanismen des Terrors blieben weitgehend die gleichen: Recherchen und Denunziationen sorgten für Gedränge in den Gefängnissen. Nach der Auflösung des ersten Comité de surveillance hatten zahlreiche ähnliche Institutionen dessen Aufgaben übernommen. Komitees im Club und in den Verwaltungen spürten jetzt die „Verdächtigen“ auf. Im Ventôse wurde erneut ein Comité de surveillance eingesetzt, welches allein im Prairial und Messidor, der Zeit der Grande Terreur, noch über hundert Personen verhaften ließ ${ }^{71}$.

Wie erfolgreich die Einschüchterungspolitik war, zeigt die massenhafte Emigration, welche Mitte November 1793 besonders in den nördlichen Gegenden des Bas-Rhin einsetzte. Nicht nur die Preußen und Österreicher, die unter General Wurmser gedient hatten, flohen vor den Revolutionsheeren, sondern auch eine immense Zahl von Bürgern und Bauern aus den besetzten Gebieten. Ihre Zahl wird auf 25-30.000 geschätzt. Für die Führung in Straßburg hatte die Massenflucht eine doppelte Bedeutung. Einerseits verbesserte sich die Versorgungslage, denn der Besitz und die Vorräte der Emigranten wurden von den Behörden eingezogen ${ }^{72}$, andererseits wuchs mit der Flucht die Zahl der Verdächtigen ins Unermeßliche. Die Anordnung des Repräsentanten Bar vom 18. Ventôse des Jahres II (8. März 1794) legte fest, daß im Distrikt Weissenburg alle Angehörigen von Emigranten festzunehmen und nach Straß-

${ }^{69}$ Eine im Entstehen begriffene Studie von Claude Betzinger zur revolutionären Justiz im Elsaß läßt auf neue Erkenntnisse in dieser Sache hoffen.

${ }^{70}$ Protokolle des Revolutionstribunals [Arch. Dépt. Bas-Rhin, 129 L 1].

"Beschluß des Repr. BAR zur Einrichtung des Comité, 16. vent. II [Arch. Nat. Paris, AF II 135, doss. 1038, 5]; Auszuige aus den Protokollen des Comité [Arch. Nat. Paris, AF II 135, doss 1040, 40] und [Arch. Dépt. Bas-Rhin 50 L 7-9]; Brief des Repr. BAUDOT an das Comité de salut public, 12 vent II [Arch. Nat. Paris, AF II 246, doss. 2105, 13].

${ }_{72}$ Anordnung der Départementsverwaltung vom 24. Jan. 1794, zit. nach: Rodolphe REUSS, La grande fuite de décembre 1793 et la situation politique et religieuse du Bas-Rhin de 1794 à 1799, Strasbourg, Oxford 1924, S. $10 \mathrm{f}$. 
burg zu bringen seien ${ }^{73}$. So füllten sich die Gefängnisse weiter. Die Emigration mag auch dazu beigetragen haben, den elsässische Widerstand in Grenzen und die Zahl der Todesopfer klein zu halten.

Der revolutionären Justiz kam die Aufgabe zu, die überfüllten Gefängnisse zu leeren. Der Forderung nach einer Beschleunigung der Justiz, welche auch die Volksgesellschaft immer wieder formulierte ${ }^{74}$, wurde am 6 . Pluviôse des Jahres II (25. Januar 1794) nachgekommen. Eine Commission ambulante sorgte für Verurteilungen nach einem Scheinproze $\beta^{75}$. Die Aufgabe, eine Bilanz der Opfer des Terrorregimes in Straßburg zu ziehen, ist noch zu lösen. Es wird von 100 Todesopfern ausgegange ${ }^{76}$. Die Zahl der Verhafteten ist schwerer festzustellen. Es dürften um die 2000 Personen gewesen sein, welche für kürzere oder längere Zeit in Straßburg im Gefängnis saßen. Ihnen sind weitere hinzuzufügen, die in die Gefängnisse anderer Départements deportiert wur$\operatorname{den}^{77}$.

In der Zeit vor dem Einsetzen des Terrors war der Druck, der von außen auf den Club wirkte, noch nicht sehr stark. Die Clubbisten paßten sich freiwillig den ideologischen Metamorphosen der jakobinischen Bewegung an, um ihre Machtansprüche vor Ort zu legitimieren. Die Zentrale legte zwar durch Gesetze die Rahmenbedingungen der lokalen Politik fest, gestand den Städten und den lokalen Führungsschichten jedoch gleichzeitig eine recht weitgehende Selbstbestimmung zu. Auch das Ausland gab schon vor dem Terror Impulse für die Straßburger Politik; doch auch sie blieben vorerst schwach. Mit den Niederlagen im ersten Koalitionskrieg und den daraufhin entsandten $R e$ présentants du peuple en mission verstärkte sich der äußere Druck auf Straßburg. In welcher Weise wirkten diese äußeren Einflüsse auf die Radikalisierung?

Zunächst ist es offensichtlich, daß sich die Ideologie der in Straßburg anwesenden Jakobiner unter dem Druck von Krieg und Krise maßgeblich veränderte. Als die Bedrohung durch den äußeren Feind akut wurde, ergänzte die jakobinische Führung rationale Deutungsmuster und Reaktionen durch irrationale. Der Glaube an eine Verschwörung der inneren Feinde stellte die Voraussetzung für die Durchführung der Schreckenspolitik dar. Die äußeren Umstände hatten also wegen spezifischer ideologischer Voraussetzungen, die vor der Terreur entstanden waren, so tiefgreifende Folgen für die innere Situation.

\footnotetext{
${ }^{73}$ REUSS, La grande fuite, S. 20.

${ }^{74}$ Extrait de la dénonciation du Sans-culotte MASSE contre Rumpler, 4 niv. II, in: Livre Bleu, Pièces à l'appui Nr. 85, Bd. 1, S. 129.

${ }^{75}$ Repr. BAUdot, LACOSTE, Beschluß vom 6 pluv. II [Arch. Nat. Paris, AF II 135, doss. 1038,31$]$.

${ }^{76}$ GREER, The Incidence of the Terror, S. 196.

${ }^{77}$ Zoltan-Etienne HARSANY, Les prisons de Strasbourg pendant la Révolution, in: Annuaire de la Société des Amis du Vieux Strasbourg 3 (1972/73), S. 107-132; 4 (1974), S. 119-139.
} 
Zweitens hat sich gezeigt, wie groß der Einfluß der Volksvertreter auf Mission war. Prägend waren sie wohl weniger auf der ideologischen Ebene, denn die Straßburger Jakobiner hatten sich stets an den Pariser Vorbildern orientiert und waren auch ohne zugereiste Volksvertreter à la hauteur de la Révolution. Die Erfahrung der Gefahr ließ lokale und von außen gekommene Jakobiner gleichzeitig den Schritt zu einer neuen Ideologie vollziehen. Zudem werden die folgenden Kapitel zeigen, daß sich die Volksrepräsentanten in ihrer ideologischen Ausrichtung immer wieder von den lokalen Gegebenheiten beeinflussen ließen. Die Volksvertreter hatten allerdings immensen Einfluß durch die konkreten Schritte, die sie einleiteten. Indem sie die Gemäßigten aus der städtischen Politik entfernten, machten sie den Weg frei für die radikalen Kräfte des Jakobinerclubs. So hatten sie den radikalen Jakobinismus in Straßburg zwar nicht geschaffen, ihm aber doch zur Durchsetzung verholfen. Indem sie die Jakobiner an die Spitze der städtischen Machtpyramide setzten, schufen sie gleichzeitig einen Kreis von willigen Helfern, die ihnen ergeben waren und es bleiben mußten, wollten sie nicht ihre Position, vielleicht sogar Freiheit und Leben verlieren. Am stärksten war der Einfluß der Volksvertreter bei der Einrichtung der Institutionen der Terreur. Jedes Bauteil der lokalen Schreckensmaschinerie hatten sie entworfen und in Gang gesetzt. Sie entwarfen die groBen Linien, während die lokalen Jakobiner diese nur umsetzten. Die unterschiedlichen Formen der lokalen Kooperation, d.h. Mitarbeit in Verwaltungen, Tribunalen und Komitees, dürfen allerdings auch nicht unterschätzt werden. Was hätten dreißig Volksvertreter ausrichten können, wenn ihnen nicht eine Gruppe von begeisterten lokalen Jakobinern zur Verfügung gestanden hätte?

\section{Die Sprache der Verschwörung}

Mit dem Beginn der Terreur hatten sich Selbst- und Feindbild erneut verändert; die exklusiven Elemente der jakobinischen Diktatur hatten sich verstärkt. Im Zuge dieser Entwicklung wurde auch der Sprache eine neue Bedeutung als Distinktionskriterium zugeschrieben: Das Französische wurde mehr und mehr auf Kosten seiner Dialekte und anderer in Frankreich gesprochener Sprachen aufgewertet; wer nicht die Sprache der Freiheit sprach, kam in den Verdacht, ein Feind zu sein. In Paris begann sich die Ablehnung von Fremdsprachen und Dialekten seit dem Oktober 1793 zu verstärken; deutlichstes Anzeichen dafür war die im Rahmen der Debatte über die nationale Erziehung aufgestellte Forderung, Französisch zur einzigen Unterrichtssprache im ganzen Land zu machen. Anfang des Jahres 1794 beschloß der Konvent, alle öffentlichen In- 
schriften ins Französische übersetzen zu lassen. Kurz darauf, am 8. Pluviôse des Jahres II (27. Januar 1794), legte Barère dem Konvent einen Bericht vor, in dem er die patois, zu denen er offenbar auch die deutsche Sprache rechnete, als Nährboden des Föderalismus bezeichnete. Aus Barères Bericht stammt auch die inzwischen berühmte Formel: Le fédéralisme et la superstition parlent bas-breton; l'émigration et la haine de la République parlent allemand; la contre-révolution parle italien et le fanatisme parle basque ${ }^{78}$. Barère überzeugte die Versammlung davon, die Übersetzungspraxis durch ein Programm sprachlicher Umerziehung zu ersetzen. Der Konvent verabschiedete daraufhin ein Gesetz, das die Entsendung von Sprachlehrern in alle Gebiete anordnete, in denen die französische Sprache nicht ausreichend verbreitet war.

Einige Monate später, am 16. Prairial (4. Juni 1794), legte Grégoire, der ja auch in früheren Sprachdebatten der Revolution in Erscheinung getreten war, einen Bericht vor, in dem er die Ergebnisse seiner 1790 begonnenen Umfrage über die patois präsentierte. Grégoire leitete aus der landesweiten Befragung $\mathrm{ab}$, daß es notwendig sei d'anéantir les patois, um gegen Fanatismus und Aberglauben zu kämpfen und so die letzten Reste des Ancien Régime zu beseitigen. Die konkreten Forderungen, welche Grégoire aus seinen Studien ableitete, waren jedoch moderat. Das Comité d'instruction solle une nouvelle grammaire et un vocabulaire nouvea ${ }^{79}$ vorlegen, um so eine Reinigung des Französischen zu bewerkstelligen.

Am 2. Thermidor (20. Juli 1794) schließlich wurde beschlossen, daß alle öffentlichen und privaten Schriftstücke in Französisch aufgesetzt werden müßten; der Sturz Robespierres verhinderte jedoch die Umsetzung dieser sprachpolitischen Maßnahme. Die Durchsetzung einer Nationalsprache wurde seit dem Januar 1794 zwar ausdrücklich und an höchster Stelle gefordert, aber nicht konsequent in ein Programm umgesetzt. Die Sprachenfrage wurde zumeist im Zusammenhang mit der nationalen Erziehung diskutiert; die Neuorganisation der Erziehung aber war ein Projekt, das seit dem Beginn der Revolution zwar häufig auf die Tagesordnung gesetzt, aber genauso häufig vertagt wurde. So gab es bis zum Ende der Terreur keine verbindlichen Richtlinien für die Sprachpolitik ${ }^{80}$.

Trotz der Unentschlossenheit der Zentrale wurden in einigen Regionen Aktionen gegen Fremdsprachen und Fremdsprachige durchgeführt. Carrier ließ keinen Zweifel daran, daß der Krieg in der Vendée auch ein Krieg gegen das

${ }^{78}$ BARERE, Rapport et projet de décret sur les idiomes étrangers [...], Paris 1794, in: Arch. Parl. 83 (1961) S. 713-717 und in: CERTEAU u. a., Une politique de la langue, S. 291-299.

${ }^{79}$ Rapport sur la nécessité et les moyens d'anéantir les patois, 16 prair. II, zit. nach CERTEAU u.a., Une politique de la langue, S. 300-317.

${ }^{80}$ Zur Sprachpoltik der Revolution: BELL, Lingua populi, lingua dei; HIGONNET, The Politics of Linguistic Terrorism; LYONS, Regionalism and Linguistic Conformity; Ders., Politics and Patois. 
Bretonische war; im Roussillon wurden katalanische Veröffentlichungen verboten und Verwalter entlassen, die nicht der französischen Sprache mächtig waren $^{81}$. Am ausgeprägtesten war die jakobinische Sprachpolitik jedoch im Elsaß, wo sich schon mehrere Monate vor der Rede Barères die Feindschaft gegen die deutsche Sprache bemerkbar machte ${ }^{82}$. In allen drei Regionen standen die Représentants du peuple an der Spitze des Angriffs auf die Sprache; ohne präzisen Auftrag schürten sie das Mißtrauen gegen alle, die sich nicht auf französisch verständigten, und trafen in Einzelfällen drastische Anordnungen. In allen drei Regionen gab es jedoch auch althergebrachtes und durch die Migrationen der Revolutionszeit erneuertes Unverständnis und kulturelle Abgrenzung zwischen den Sprachwelten, die von den Machern des Terrors im Zeichen der Verschwörungstheorien aufgegriffen und in propagandistische Waffen verwandelt werden konnten.

Was bewog den Konvent und die lokalen Machthaber, sich der Sprachenfrage zu widmen, die angesichts der doppelten Krise doch eher nebensächlich erscheint? Eine einfache Erklärung für die Einführung kultureller Kriterien in die Selbst- und Feinddefinition gibt es nicht. Patrice Higonnet stellt die These auf, daß die Forderung nach sprachlicher Einheit ein Ausweichmanöver war, das durchgeführt wurde, weil sich die soziale Gleichheit im Verlauf des Jahres 1793 als zu problematisch herausgestellt hatte ${ }^{83}$. Eine solche Annahme läßt sich vielleicht aus dem Pariser Kontext ableiten; die Straßburger Situation, in der der Ruf nach der Einheitssprache tiefe Gräben riß und gerade nicht zu neuer Einheit führte, legt eher andere Erklärungsmuster nahe. Im folgenden wird untersucht, ob die Sprachpolitik der Représentants du peuple sich nicht eher aus der Tatsache erklärt, daß diese gezwungen waren, sich eine tragfähige lokale Basis zu schaffen und daher die französische Sprache als Bindemittel für eine loyale Gefolgschaft nutzten. Zu diskutieren ist jedoch auch Sophie Wahnichs Ansatz, daß der Wunsch nach einer einheitlichen Kultur aus der in der vorrevolutionären französischen Gesellschaft verbreiteten mißtrauischen Haltung gegenüber den „Fremden" entstanden $\mathrm{sei}^{84}$, die nicht nur bei den Volksvertretern, sondern auch bei Teilen der in Straßburg tätigen ,einfachen Jakobiner" anzutreffen war.

Im Rahmen dieser Studie über Radikalisierungsprozesse ist es zentral, die Rolle zu analysieren, welche die Sprache in der jakobinischen Einheitsdefinition spielte. Das folgende Kapitel nähert sich dem Problem auf verschiedenen Wegen: Zunächst wird der anti-deutsche Diskurs und seine schrittweise Verschärfung untersucht: In Straßburg änderte sich zunächst die Haltung gegen-

${ }^{81}$ Michel BRUNET, Le Roussillon: Une société contre l'État, 1780-1820, Perpignan 1990.

${ }^{82}$ Zum Sprachterror im Elsaß: MCCOY, The Société Populaire at Sainte-Marie-aux-Mines; PELZER, Die Wiederkehr des girondistischen Helden, S. $68 \mathrm{ff}$.

${ }^{83}$ HigONNET, The Politics of Linguistic Terrorism.

${ }^{84}$ WAHNICH, L'impossible citoyen, S. $14 \mathrm{f}$. 
über den deutschen Nachbarn, danach gegenüber den Ausländern im eigenen Land; erst dann setzte das Mißtrauen gegenüber den germanophonen Elsässern ein. In einem zweiten Schritt werden die konkreten Maßnahmen gegen die deutsche Sprache und die Germanophonen dargestellt; es wird gefragt, ob im Elsaß tatsächlich von einer terreur linguistique gesprochen werden kann. Schließlich werden die Protagonisten der Germanophobie und ihre Motive untersucht; Ziel ist es, lokale und von außen kommende Impulse zu unterscheiden und die oben angerissenen Thesen am konkreten Fallbeispiel zu diskutieren.

\section{Von Außen nach Innen - die Verknüpfung sprachlich fundierter Feindbilder}

Am Anfang des Jahres 1793 war der Blick auf das Ausland noch von der Doktrin des Befreiungskrieges geprägt; das Bild vom ,bösen“ deutschen Fürsten und die Vorstellung eines "guten“ deutschen Volkes, das es zu befreien galt, standen unverbunden nebeneinander. Im März 1793, als in Mainz der rheinisch-deutsche Nationalkonvent gewählt wurde, war in Straßburg der Glaube an die Verbrüderung der Völker schwächer geworden, aber noch nicht völlig verschwunden. Im Courrier de Strasbourg hieß es: Aujourd'hui toute l'Europe est conjurée contre nous, im gleichen Artikel wurde jedoch der Hoffnung Ausdruck verliehen, daß Völkerfreundschaft noch möglich sei:

A la première conscription militaire aucun peuple voisin n'élevoit son cœur vers la liberté; aucune nation ne nous appeloit à son appui; mais aujourd'hui tous les peuples s'éclairent: déjà le Savoisien, le Belge, le Mayençois, le Rauraque, sont libres: L'Allemand, si attaché à ses préjugés, en sent toute la foiblesse, il nous attend en silence; L'Anglois, l'Irlandois, qui ne veulent plus d'une demi-liberté, nous souhaitent prosperité et succès: ils nous tendent les bras; le Batave flegmatique nous appelle; ainsi rien ne nous retient plus dans l'intérieur; et le danger de la patrie et la destuction de la tyrannie, et l'établissement de la liberté universelle, nous appellent au dehors ${ }^{85}$.

Trotz des Krieges wurde hier noch am Glauben an eine Verbrüderung mit einigen Völkern festgehalten. Wie in der Zeit des Befreiungskrieges wurde die Passivität der Deutschen betont, welche zwar für die Revolution seien, aber nicht bereit, für sie zu kämpfen. Auch der Argos äußerte sich in dieser Zeit noch vergleichsweise optimistisch: Ganz Europa hat uns angegriffen! ruft ihr, allein verbündet mit den Völkern, welche zwischen Euch und dem Rhein wohnen, steht ihr [...] furchtbar und kühn vor den übrigen sehr verstreuten Natio-

${ }^{85}$ Art. „Strasbourg. Société des Jacobins. Discours prononcé par un citoyen, après la lecture du décret de la convention sur les recrutements.“, in: Courrier de Strasbourg, Nr. 58, 8. März 1793. 
nen, sie kämpfen für Vorurteile und Despotismus, ihr kämpft für Menschenrechte und Freiheit ${ }^{86}$. Nicht mehr alle Völker, sondern nur noch die Rheinländer waren jetzt Verbündete. Beide Zitate illustrieren, wie der Glaube an die internationale Gemeinschaft der Revolutionsanhänger zu schwinden begann.

Eulogius Schneider griff in einem Gedicht die aufgeklärten deutschen Eliten an, welche sich nicht in ausreichendem Maße an Frankreichs Kampf für die Freiheit beteiligt hätten. Die gereimte Epistel an Professor Feder zu Würzburg, die vor der Terreur entstand, im Herbst 1793 jedoch erneut veröffentlicht wurde, beschreibt den deutschen Gelehrten als zu feige, seine politischen Überzeugungen in die Tat umzusetzen. Wichtiger als das Leben nach seinen Idealen sind Professor Feder Titel [...] Fürstengunst und Geld. Er beugt sich der Angst, beschäftigt sich mit Hände falten, mit tiefgesenktem Haupte gehen, gewissenhaft die Fasten halten, und niemand in die Augen sehen ${ }^{87}$.

Nach dem Ende der Mainzer Republik im Juli und gleichzeitig mit dem stetigen Vorrücken der preußisch-österreichischen Armeen auf französischem Gebiet wandelte sich das Deutschlandbild. Ausdruck für die neue Haltung zum Nachbarn war die Propaganda der Représentants du peuple en mission; in ihren Aufrufen zur levée en masse schlugen sie einen ganz neuen Ton an. Sie beschrieben den Deutschen nur noch als feindlichen Soldaten; sie bezeichneten ihn als esclave armé $e^{-88}$, dessen bloße Anwesenheit den heiligen Boden der Freiheit besudele. Die Deutschen seien vils serpens ${ }^{89}$, die nicht durch ihre Kraft, sondern nur durch Betrug siegen können; sie seien automates stipendiés $^{90}$, die gefühllos und zu jeglicher Grausamkeit fähig seien. Dieser Hang, die Feinde zu entmenschlichen oder zu barbarisieren, verstärkte sich, je größer die Gefahr für Frankreich wurde. Bald waren die Soldaten des Reiches brigands barbares, autrichiens antropophages und cannibales effrénés, welche in elsässischen Dörfern friedlichen Bürgern die Augen ausdrückten, die Hände abschnitten, stillende Mütter und Schwangere mordeten und Alte und Kinder niedermetzelten ${ }^{91}$.

Berichte über die Behandlung der französischen Kriegsgefangenen in Deutschland, deren Wahrheitsgehalt kaum zu überprüfen war und ist, bestätigten das Bild von den barbarischen Deutschen. Am 25. August 1793 erreichte die Gesellschaft ein Schreiben vom Hagenauer Distriktsdirektorium, das die Leiden der bei der Rückeroberung von Frankfurt gefangengenommenen Fran-

\footnotetext{
${ }^{86}$ Art. „Bei Gelegenheit des Unfalls vor Aachen“, in: Argos, Nr. 29, 23. März 1793.

${ }^{87}$ Argos, Nr. 1, 4 niv. II.

${ }^{88}$ Repr. Milhaud, RUAMPS, BorIE, Proclamation des Représentans du Peuple près l'armée du Rhin, 17 août 1793 [Arch. Nat. Paris, AF II 248, doss. 2114, 8].

${ }^{89}$ Ibid.

${ }^{90}$ Ibid.

${ }^{91}$ Repr. Milhaud, Ruamps, Borie, Proclamation du 22 Aout 1793, l'an second de la République Française. Aux armes républicains aux armes! [Arch. Nat. Paris, AF II 248, doss. $2114,35]$.
} 
zosen beschrieb: Ce n'est pas assez pour le barbare Autrichien de priver un Français de sa liberté, à l'esclavage il ajoute la cruauté et l'ignominie. Tigres dénaturés, frémissez! $!^{92}$ Der Unterschied zwischen deutschen Tyrannen und deutschem Volk, welcher die Doktrin des Befreiungskrieges begründet hatte, verlor nun an Bedeutung; die Deutschen wurden kollektiv als un peuple sauvage et féroce ${ }^{93}$ bezeichnet; die verschiedenen Begriffe les Allemands, les Autrichiens, les Prussiens, l'Empire bezeichneten gleichermaßen ein homogenes feindliches Kollektiv. Als der Argos am 28. September 1793 den Blick auf die gegenwärtige Lage Europa's richtete, war rundum kein Helfer mehr in Sicht, die feindliche Front um Frankreich war geschlossen: Finsternis umhüllt uns ${ }^{94}$.

Die Deutschen, jetzt als ein Volk von grausamen Soldaten angesehen, hatten sich auf die Seite der Fürsten gestellt. Sie wurden nicht mehr als passiv, sondern als aktiv dargestellt; ihre Aktivitäten waren allerdings gegen die Revolution gerichtet. 1790/91 war es eine Handvoll deutscher Jakobiner, welche die Straßburger Clubbisten von der allgemeinen deutschen Revolutionsbegeisterung überzeugte; 1793 waren es die Soldaten, von derem wirklichen oder imaginierten Verhalten man auf den Willen des gesamten deutschen Volkes schließen zu können glaubte. Eine selektive Wahrnehmung war von einer anderen abgelöst worden. Das neue Bild von den Deutschen als gräßlichen Feinden, das zuerst die Volksrepräsentanten verbreiteten, hielt wenig später auch im Club Einzug. Aus dem haßerfüllten Blick auf Deutschland erklärt sich der im Straßburger Club gestellte Antrag, daß die verwundeten französischen Soldaten nicht dans l'air pestiféré des Autrichiens et des Prussiens ${ }^{95}$ geheilt werden könnten.

Die aktive und erfolgreiche Beteiligung Englands am Krieg gegen Frankreich erweiterte den Kreis der äußeren Feinde ${ }^{96}$. Bei einer Feier der Jakobiner zum Jahrestag des Todes von Ludwig XVI. träumte ein Redner davon, que dans la place où Londres est bâtie, il ne reste plus que ces mots terribles, écrits en caractères de sang: La nation française a vengé l'humanité sur les fëroces Anglais. Vive la République, vive la liberte ${ }^{-97}$. In einem Flugblatt der Munizipalität, das die Straßburger zu Spenden für ein Kriegsschiff gegen England aufrief, hieß es: La scélératesse du gouvernement anglais est à son comble! C'est lui qui est le principal auteur des maux que nous avons soufferts depuis plusieurs années. Les Républicains ont juré la destruction de cette île souillée de tant de crimes. Serez-vous indifférents, citoyens, dans ce combat à mort

\footnotetext{
${ }^{92}$ Brief des Districtsdirektoriums von Hagenau, in: HEITZ, Les sociétés politiques, S. 275.

${ }^{93}$ Ibid.

${ }^{94}$ Art. „Blick auf die gegenwärtige Lage Europa's“, in: Argos, Nr. 39, 28. September 1793.

${ }^{95}$ Clubprotokoll vom 10. Jan. 1794, in: HEITZ, Les sociétés politiques, S. 319.

${ }^{96}$ Norman HAMPSON, The Perfidy of Albion. French Perceptions of England during the French Revolution, New York 1998.

${ }^{97}$ Clubprotokoll vom 8. Feb. 1794, in: HEITZ, Les sociétés politiques, S. 327.
} 
avec les esclaves de la perfide Albion $?^{98}$ Auch wenn die aus Deutschland drohende Gefahr deutlich größer war, imitierte man die aus Paris kommende antibritische Rhetorik ${ }^{99}$. Die Anglophobie erreichte an der Ostgrenze jedoch nicht das gleiche Ausmaß wie in der Hauptstadt.

Die neue Abneigung gegen Deutschland bekamen als erstes die Deutschen zu spüren, welche sich in Frankreich aufhielten. Die anfängliche Offenheit gegenüber den „Aposteln der Freiheit“ aus aller Herren Länder verschwand. Die étrangers wurden nun verdächtigt, mit den äußeren Feinden verschworen zu sein. Das Gesetz vom 6. September 1793 gab den Volksvertretern Mittel an die Hand, um gegen Fremde vorzugehen. Es legte fest, daß alle Ausländer aus Ländern, mit denen Frankreich im Krieg stand, interniert werden mußten. Ausgenommen waren nur Arbeiter in Werkstätten und Ausländer, die besondere Proben ihres Bürgersinns abgelegt hatten. Zur Überprüfung der politischen Verläßlichkeit der Ausländer wurden die Hospitalitätskarten eingeführt ${ }^{100}$. Auch der Club machte sich die neue Haltung zu eigen; erst im April 1794 beschlossen seine Mitglieder allerdings, Ausländer prinzipiell aus ihren Reihen auszuschließen ${ }^{101}$.

Aus der Ablehnung gegen Deutsche und Fremde als Verschwörer entstanden im Herbst 1793 Ressentiments gegen die Elsässer, die wegen ihrer historischen und kulturellen Bindung ans Reich verdächtigt wurden, auch zur Verschwörung zu gehören. Den Elsässern wurde unterstellt, nach wie vor ihren alten deutschen Herren nachzutrauern: La partie de la République, qui formoit la cidevant Alsace et principalement le département du Bas-Rhin, étoit peuplée d'une masse d'individus plus attachés aux tyrans de l'Autriche, qu'à la République française, qui conspiroient nuit et jour, pour rentrer sous la domination de leurs ancien maîtres ${ }^{102}$, beschrieben die Repräsentanten Lacoste und Baudot den Zustand des Bas-Rhin bei ihrer Ankunft. Ähnlich äußerte sich Lacoste in einem anderen Brief an den Wohlfahrtsausschuß:

Le Comité de Salut public n'ignore pas que depuis longtems l'Alsace étoit vendue aux Autrichiens, comme Toulon aux Anglais; et que si la ville de Strasbourg n'a pas subi le même sort, il doit considérer sa conservation, comme un grand bonheur pour la République. [...] Le Comité n'ignore pas que dans la ville de Strasbourg il n'y a pas quatre patriotes; que les trois

\footnotetext{
${ }^{98}$ Adresse des Corps municipal vom 24. Juli 1794, in: HEITZ, Les sociétés politiqes, S. 359.

${ }^{99}$ Sophie WAHNICH, La notion d'étranger en l'an II: Les constructions d'un dialogue ParisProvince dans les Archives parlementaires, in: AHRF 62 (1990) S. 379-403.

${ }^{100}$ Art. „National-Konvent. Freitags-Sitzung, den 6ten September“, in: Straßburgische Zeitung, Nr. 217, 12. Sept. 1793.

${ }_{101}$ Clubprotokoll vom 23. April 1794, in: HEITZ, Les sociétés politiques, S. 342.

${ }^{102}$ Repr. Lacoste, Baudot, Bericht an das Comité de Salut public vom 6 pluv. II [Arch. Nat. Paris, AF II 135, doss. 1038, 31 ].
} 
quarts des habitans du département du Bas-Rhin ne sont point françois, mais plutôt autrichiens, et détestent la révolution françoise ${ }^{103}$.

Auch Monet, der jakobinische Bürgermeister von Straßburg, attestierte den Elsässern eine grundsätzliche und alte Abneigung gegen die Franzosen:

La principale cause des succès, que les factions avaient obtenus dans le Bas-Rhin, est dans l'antipathie invétérée des habitans contre les Français et leur tendance trop marquée vers le germanisme; le titre de Français ou de Velche était n'aguères une sorte d'insulte; celui d'Allemand annonçait un compatriote, auquel l'amitié devait un accueil fraternel. L'Alsace, avant la révolution, réunie depuis peu de tems à la France, avait conservé ses anciennes mours, son costume, son langage, et une jurisdiciton particulière [...] Conservant avec soin les tableaux gothiques de leurs ancêtres, elles [die wohlhabenden elsässischen Familien] ne s'unissaient qu'entr'elles et repoussaient avec fierté l'alliance des français, qu'elles regardaient comme les $\mathrm{Pa}$ rias de l'Inde. [...] Le sol était français, mais les coeurs appartenaient à l'Autriche ${ }^{104}$.

Auch Monet führte also historische und kulturelle Gegebenheiten an, um die politische Unzuverlässigkeit der Elsässer zu belegen. Darüber hinaus glaubten die Jakobiner an einen „Charakter“, der allen germanischen Völkern eigen sei und sie für die Freiheit unempfänglich mache. So schrieb der Jakobiner Daniel Stamm über die Bürger von Benfeld: Les habitans de ce pays [...] sont très labourieux, interessés mais sans energie. [...] L'esprit public est généralement nul, et le devouement luy est inconnu, s'est avec peine que le cultivateur et le vigneron se fait au nouvel ordre des choses ${ }^{105}$. Einen ähnlichen „Charakter" glaubte der Jakobiner Gottekien bei Teilen des Landvolkes zu erkennen:

Le peuple de la campagne du District de Benfeld est naturellement bon, laborieux et excellent agriculteur, mais égoiste et fanatique la majeure partie n'a aucune notion du nouvel ordre des choses, c'est des êtres purement passifs qui n'agissent que par impulsion étrangère, fortement attachés aux anciens préjugés, idolâtres de la superstition sacerdotale, ils sacrifieraient tout pour avoir des prêtres, sans lequels ils se croient perdus ${ }^{106}$.

${ }^{103}$ LACOSTE an das Comité de Salut public vom 28 frim. II [Arch. Nat. Paris, AF II 247, doss. 2110, 45].

${ }^{104}$ Pierre François MONET, Discours sur la conjuration de l'étranger dans le Bas-Rhin, prononcé à la société populaire de Strasbourg, 18 flor. II, in: Livre Bleu, Pièces à l'appui Nr. 69, Bd. 1, S. 99f.

${ }^{105}$ Daniel STAMM, Bericht ohne Datum und Adressaten [Arch. Nat. Paris, AF II 135, doss. $1041,5]$.

${ }^{106}$ GotTEKIEn, Apercû, ohne Datum und Adressaten [Arch. Nat. Paris, AF II 135, doss. $1041,6]$. 
Monet diagnostizierte:

Un phlegme assoupissant, une âme sans énergie, le dedain de l'orgueil annonçaient l'habitant du pays et décélaient son origine primitive; ainsi l'éducation, l'habitude, l'amour, les affections les plus chères semblaient conspirer contre la patrie ${ }^{107}$.

Die Elsässer zeichneten sich also nach Meinung der Jakobiner vor allem durch Untertanengeist aus. Dies war die Voraussetzung dafür, daß die Elsässer für die Einflüsterungen des Fanatismus und der Konterrevolution und später der germanophonen Verschwörung offen waren:

Le peuple du Bas-Rhin, naturellement bon et crédule, a été égaré. D'après ce que nous avons vu, d'après les preuves que nous avons acquises, nous ne pouvons plus douter aujourd'hui que tous les coups que frappoit à Paris le comité Autrichien, ne vinissent retentir d'une manière alarmante à Strasbourg. Tout a été tenté pour en séduire les habitans: pendant que l'aristocratie et le fanatisme soulevoient d'un côté la masse des anciens préjugés, le fayettisme, la bassesse, la cupidité, le royalisme se réunissoient de l'autre pour amortir le patriotisme et rendre nuls les efforts. [...] La révolution du 10 août a fait disparoitre, dans le reste de la France, les nuages qui enveloppoient la liberté et en interceptioent les rayons. [...] A Strasbourg ces nuages subsistent encore, et ne disparoitront qu'avec ceux qui les avoient amoncelés. Le peuple n'embrassera la République avec enthousiasme, que lorsqu'il sera dirigé par ceux qui ont contribué à l'établir ${ }^{108}$.

Die Konstruktion eines deutsch-elsässischen „Charakters“, in dem sich zum einen Brutalität und Verschlagenheit, zum anderen Passivität, Desinteresse und Verführbarkeit mit konterrevolutionären Absichten verbanden, markierte das Ende des einstigen Glaubens an die Vereinbarkeit von politischer Einheit und kultureller Vielfalt. Politische Meinungen wurden nun nicht mehr als das Ergebnis einer freien Entscheidung, sondern als Folge einer kulturellen Prägung verstanden. Deshalb erschien den radikalsten Jakobinern die Distanzierung von allen, die von dieser Kultur geprägt waren, als einzig richtiger Weg.

${ }^{107}$ MONET, Discours sur la conjuration de l'étranger, S. 100.

${ }^{108}$ Lettre des citoyens Commissaires Députés de la Convention nationale, dans les Départements de la Meurthe, de la Moselle et du Bas-Rhin, adressée à la Municipalité de Strasbourg, 11. Feb. 1793 [Arch. Dépt. Bas-Rhin, 1 L 728]. 


\section{Gab es einen Sprachterror?}

Die verbalen Angriffe auf die deutsche Sprache und ihre Sprecher hatten auch greifbare Folgen. In der kollektiven Erinnerung der Straßburger ist vor allem die Anordung der Repräsentanten Saint-Just und Lebas haften geblieben, die Straßburgerinnen sollten sich nicht mehr nach der deutschen Mode kleiden, da ihre Herzen französisch seien ${ }^{109}$. Die deutschsprachige Straßburgische Zeitung bemerkte dazu billigend: Wie müßten unsere Jünglinge, wenn sie einst siegreich aus der Schlacht zurückkehren, sich freuen, daß ihre Schönen nun auch im äußerlichen Patrioten sind ${ }^{110}$. Am folgenden Tag forderten die Repräsentanten die elsässischen Frauen auf, ihren traditionellen Festtagsschmuck, die goldenen Schneppenhauben, als Spende für den Krieg abzugeben ${ }^{111}$.

Die überzeugtesten Jakobiner in Straßburg machten Vorschläge, wie die deutsche Sprache aus dem öffentlichen Leben zu verdrängen sei. Im Club wurde dies zum ersten Mal am 17. Dezember deutlich, als der Repräsentant Baudot erklärte, es sei absurd, eine Rede zur Erinnerung an Marat und Le Peletier in der Sprache der Österreicher, Preussen, der Feinde unserer Frei$h i t^{112} \mathrm{zu}$ halten. Auch der Einwand, die meisten Clubmitglieder könnten der Rede nicht folgen, wenn sie in französisch wäre, ließ Baudot nicht von seiner Anordnung abrücken. In der Clubsitzung vom 25. November 1793 wurde über die Alsaciens qui ne connaissent point la langue française et que leur idiome isole du reste de la République diskutiert. Ein Mitglied schlug vor, die Elsässer zu deportieren und an ihrer Stelle eine Kolonie von Sansculotten im Elsaß anzusiedeln, ein anderes, für die Germanophonen eine promenade à la guilloti$n e^{113} \mathrm{zu}$ veranstalten.

Solche Projekte wurden auch dann noch anvisiert, als der Krieg mit dem Reich für Frankreich keine Bedrohung mehr darstellte. Am 23. Dezember 1793 forderte der Jakobiner Delâtre:

Frères, quoique la nouvelle de la victoire remportée doit réjouir tout Républicain, cette joie ne doit pas laisser s'endormir. Les attaques des Prussiens et des Autrichiens ne sont que des ombres, en comparaison du plan d'une grande partie des suspects que nous avons dans notre ville, renfermés dans l'édifice que nous nommons Séminaire. Je fais donc la motion de demander

${ }^{109}$ Repr. SAINT-JUST, LEBAS, Anordnung vom 25 Brum. II: „Les citoyennes de Strasbourg sont invitées de quitter les modes allemandes, puisque leurs coeurs sont français." in: Livre Bleu, Pièces à l'appui Nr. 31, Bd. 1, S. 20.

${ }^{110}$ Art. „Strasburg“, in: Straßburgische Zeitung, Nr. 272, 29 brum. II.

${ }^{1 i 1}$ Art. ,Straßburg", in: Straßburgische Zeitung, Nr. 270, 26 brum. II.

${ }^{112}$ Clubprotokoll vom 17. Dez. 1793, in: HEITZ, Les sociétés politiques, S. 311.

${ }^{113}$ Clubprotokoll vom 25. Nov. 1793, in: HEITZ, Les sociétés politiques, S. $302 f$. 
au Représentants de faire conduire ses personnes à l'intérieur de la République $^{114}$.

Später mahnte der Repräsentant Lacoste, die Elsässer in keinem Fall ohne Aufsicht zu lassen:

Si sans retard il n'est point jetté dans la ville de Strasbourg une garnison de quatre mille sansculottes pris en dehors du Département, si toutes les autorités constitués, les fonctionnaires publics ne sont point renouvellés par des bons jacobins, aussi pris au dela des limites de ce département; si l'on ne chasse point de cette forteresse au moins six mille aristocrates feuillans ou intriguans qu'elle recèle dans l'enceinte de ses remparts, si la langue allemande n'est proscrite et des institution établies pour apprendre celle de la République, on ne peut répondre de lui conserver le principal boulevard ${ }^{115}$.

Auch der Jakobiner Boy forderte in einer Ansprache im Tempel der Vernunft eine Bekehrung des Elsaß zur Republik, dazu seien moyens indispensables de rigueur ${ }^{116}$ nötig. Es sei nicht länger möglich, eine wichtige Grenze einem Volk zu überlassen, das sich durch l'habitude de l'esclavage, le pouvoir du fanatisme, la corruption ${ }^{117}$ auszeichne. Boy drohte den Elsässern mit der Vertreibung: Le sol fertile que vous habitez deviendra le partage des braves Sansculottes, et vous en serez chassés avec ignominie. Quelle serait alors votre ressource ${ }^{118}$.

Auch von anderen Gesellschaften aus Frankreich kam der Vorschlag, das Elsaß zu entvölkern; in einer Zuschrift der Volksgesellschaft von Blamont hieß es:

Les départements des Haut-et Bas-Rhin ont toujours recelé une foule de traitres et de conspirateurs. Nous venons de voir le moment terrible où Strasbourg devoit être livré aux tyrans couronnés par ces scélérats. Eh bien, citoyens, la plupart de ces monstres existent encore. Ils pensent se soustraire à la vengeance du peuple en singeant le patriotisme. Mais faisons paroître leur perfidie dans tout son jour [...]. Réunissez vous à nous pour solliciter la déportation dans l'intérieur de la République de tous les habitans des haut et bas Rhin, qui dès le commencement de la révolution n'ont pas montré un patriotisme décidé. Qu'ils sentent les remords, qu'ils pleurent leurs crimes, qu'ils voyent la liberté des autres, qu'ils sentent qu'ils ont justement perdu la

${ }^{114}$ Clubprotokoll vom 23. Dez. 1793, in: HEITZ, Les sociétés politiques, S. 313.

${ }^{115}$ Repr. LACOSTE an das Comité de Salut public, 28 frimaire [Arch. Nat. Paris, AF II 247, doss. 2110, 45].

${ }^{116}$ Discours prononcé dans le Temple de la Raison de Strasbourg, 30 pluv. II, par le citoyen BOY [Bibl. Nat. Univ. Str., M 5514].

${ }^{117}$ Ibid.

${ }^{118}$ Ibid. 
leur, et qu'ils vengent par cet équitable suplice la majesté de la nature qu'il outragèrent et la sainteté des loix sociales qu'ils osèrent violer ${ }^{119}$.

Am 6. Mai 1794 stellte der Jakobiner Simon einen Bericht des Comité de l'instruction des Straßburger Clubs vor, der darauf abzielte, die Französisierung des Elsaß' zu beschleunigen. Auch das Komitee schlug vor, verdienten Bürgern aus dem Inland den Kauf von Nationalgütern im Elsaß zu erleichtern und die Elsässer zum Kauf im Innern zu ermutigen ${ }^{120}$. Der Repräsentant Rousseville regte in seiner Dissertation sur la Francilisation de la ci-devant Alsace an, junge Elsässer bei französischen Familien im Landesinneren einzuquartieren $^{121}$. Es fehlte also offenbar nicht an radikalen Plänen zur Französisierung. Doch keiner von ihnen wurde in die Tat umgesetzt. Das Reden von Deportation und Umsiedlung blieb, ebenso wie die Andeutung über die Durchführung von noyades wie in der Vendée ${ }^{122}$, eine leere Drohung, die allerdings, wie die massenhafte Emigration bewies, ihre Wirkung nicht verfehlte. Auch die Umsetzung der Erziehungspläne des Konvents vollzog sich nur schleppend. Der Plan, durch den öffentlichen Unterricht die Verbreitung der französischen Sprache zu befördern, wurde nur in Ansätzen durchgeführt. Grundlage der Erziehungsreform war das Gesetz vom 19. Frimaire des Jahres II (9. Dezember 1793). Der Repräsentant Saint-Just reagierte auf das Gesetz, das zunächst ohne feste Ausführungsvorschriften blieb, am 9. Nivôse (29. Dezember 1793) mit dem Befehl, in jeder Gemeinde des Bas-Rhin kostenlose Sprachschulen einzurichten. Er stellte dafür 600.000 livres aus der Anleihe bei den Reichen zur Verfügung ${ }^{123}$. Kurz darauf sekundierte ihm der Konvent mit dem Gesetz vom 8. Pluviôse (27. Januar 1794), in dem festgelegt wurde, daß jede Kommune im Département Haut-Rhin, Bas-Rhin und Moselle innerhalb von acht Tagen einen Lehrer anstellen sollte, der Primärschüler in französisch unterrichten könne. Die jakobinische Partei begrüßte den Entschluß enthusiastisch:

L'éducation nationale, uniforme dans tous les départemens, commune à tous les citoyens, contribuera aussi à réformer promptement le caractère et les mœurs, si-non de la génération présente, au moins de celle qui lui succède. L'on ne saurait assez applaudir au décret sage et politique, qui établit dans chaque commune des écoles de langue française, rendre cette langue familière, bannir l'allemande du commerce et de tous les actes publics, l'extirper insensiblement, proscrire le costume et les mours étrangères, c'est briser

\footnotetext{
${ }^{119}$ Brief der Volksgesellschaft von Blamont (Doubs), 29 niv. II [Arch. Mun. Str., Fonds 3/9, 158].

${ }^{120}$ Clubprotokoll vom 6. Mai 1794, in: HeITZ, Les sociétés politiques, S. 348.

${ }^{121}$ RouSSEville, Dissertation sur la Francilisation de la ci-devant Alsace [Bibl. Nat. Univ. Str., M 6599]

${ }^{122}$ Bernard VINOT, Saint-Just, Stuttgart 1989, S. 192.

${ }^{123}$ Repr. SAINT-JUST, Arrêté, 9 niv. II [Arch. Nat. Paris, AF II 135, doss. 1044, 38].
} 
autant de nouds qui unissent le Bas-Rhin à l'ennemi; c'est élever un mur de séparation éternelle entre les hommes libres et les esclaves, c'est identifier enfin l'Alsace à la République ${ }^{124}$.

Die Umsetzung dieser Beschlüsse erwies sich jedoch als ausgesprochen langwierig. Am 20. April 1794 meldete der Club, der mit der Suche von geeigneten Lehrern beauftragt war, qu'il ne s'est présenté jusqu'à présent qu'un très-petit nombre d'instituteurs de langue française pour les écoles de la campagne ${ }^{125}$. Im Mai hatte man für 29 Gemeinden des Distrikts Straßburg Französischlehrer gefunden. Die Verwaltung traute jedoch den neuen Lehrkräften nicht und ordnete deshalb an, die schon Eingestellten binnen acht Tagen nach Straßburg zu schicken, um dort ihre Bürgertugenden und ihre pädagogischen Fähigkeiten zu prüfen. Voraussetzung für die Einstellung sollte von nun an ein gültiges certificat de civisme sein. Weiterhin sollten die Schulen in den Gemeinden in regelmäßigen Abständen von Kommissaren der Verwaltung besucht und kontrolliert werden ${ }^{126}$.

An Polemiken gegen die deutsche Sprache und die elsässische Kultur, an Umerziehungsplänen und an einzelnen Aktionen gegen Germanophone mangelte es also nicht. Dennoch wäre es übertrieben, von einer systematischen Ausgrenzungs- oder gar Vernichtungspolitik gegen die im Lande befindlichen Germanophonen zu sprechen. Die Verwendung der deutschen Sprache in Wort und Schrift war verpönt, aber nie tatsächlich verboten. Auch im Winter 1793/94 wurden in Straßburg deutsche Zeitungen gedruckt, so zum Beispiel die jakobinisierte Straßburgische Zeitung oder der Argos. Selbst amtliche Verlautbarungen erschienen teilweise weiterhin in zwei Sprachen. Die Pläne zur sprachlichen Umerziehung wurden nur ansatzweise durchgesetzt. Vor allem ist jedoch festzuhalten, daß sogar die wortgewaltigsten Verfechter der Francisation weiterhin wichtige Posten an deutschsprachige und sogar an deutsche Jakobiner verteilten. Auch gibt es keine Hinweise darauf, daß überdurchschnittlich viele Germanophone unter der Guillotine starben. Es gab also einen ausgeprägten germanophoben Diskurs, aber nur in Ansätzen eine terreur linguistique.

\section{Ursachen der Germanophobie}

Die in den letzten Abschnitten zitierten germanophoben Äußerungen stammten aus dem Mund von zwei Gruppen: Am vehementesten attackierte ein recht übersichtlicher Kreis von Volksvertretern auf Mission - Milhaud, Ruamps,

${ }^{124}$ MONET, Discours sur la conjuration de l'étranger, S. 102.

${ }^{125}$ Clubprotokoll vom 20. Avril 1794, in: HEITZ, Les sociétés politiques, S. 341.

${ }^{126}$ Délibération du Directoire du District de Strasbourg, du 24 Floréal II (13. Mai 1794) [Arch. Nat. Paris, AF II 135, 1044, 2]. 
Borie, Lacoste, Baudot, Saint-Just und Lebas alles deutsche; daneben existierte eine zweite tragende Gruppe, zu der lokale Führerfiguren wie Monet und weniger bekannte, vor Ort aktive frankophone Jakobiner zu zählen sind. Welche Funktion hatte der anti-deutsche und anti-elsässische Diskurs für beide Gruppen? Gibt es trotz des starken Einflusses der Volksvertreter Anlaß, von lokalen Wurzeln desselben auszugehen?

Was die Volksvertreter anbetrifft, so scheinen sie verschiedene ineinander verschränkte Motive für ihre Ausfälle gehabt zu haben. Im Sommer 1793 schürten sie den $\mathrm{Ha}$ gegen die Deutschen, um die levée en masse in Schwung zu bringen. Zu dieser Zeit, in der vor allem der äußere Gegner anvisiert wurde, gab es noch keine sprachlich fundierten anti-elsässischen Ressentiments. Diese entstanden erst im Herbst 1793, etwa zeitgleich mit dem Näherrücken der Front an Straßburg und der damit einhergehenden Ausbreitung der Verschwörungsphobie. Um das Szenario einer Komplizenschaft von inneren und äußeren Feinden plausibel zu machen, bedurfte es greifbarer und sichtbarer Indizien; die Konstruktion einer Sprache der Verschwörung bot sich an.

Darüber hinaus stellte sich die Sprachenfrage aber auch bei den Bemühungen der Volksvertreter, eine ganz und gar verläßliche und bedingungslos funktionierende lokale Führungsschicht zu etablieren. Aktivisten, die Schwierigkeiten hatten, Befehle genau zu verstehen, und die nicht mit Verve die Sprache der neuen Zeit sprechen konnten, empfahlen sich nicht als Gefolgsleute. Sie erschienen als unbrauchbar und konnten deshalb ohne Verlust ausgegrenzt werden. Frankophone Mitglieder gab es im Straßburger Jakobinerclub genug; dies lag unter anderem daran, daß der Anteil der aus Innerfrankreich Immigrierten immer weiter anstieg. Schon 1792 waren $35 \%$ der neu vereidigten Jakobiner im Inneren Frankreichs geboren; 1793 machten Franzosen 55\%, 1794 sogar $60 \%$ der Beitritte aus ${ }^{127}$. Das frühe Einsetzen dieser Entwicklung spricht dafür, daß es nicht die Germanophobie war, die sie auslöste, sondern vielmehr das wachsende Desinteresse der autochthonen Straßburger. Sie wurde jedoch in der Terrorzeit durch gezielte Anwerbung von innerfranzösischen Jakobinern verstärkt. Bestes Beispiel dafür ist die Gründung der sogenannten Propagande révolutionnaire, welche Straßburg wieder auf die Höhe der Revolution bringen sollte: Il faut que de tous les points de la République, des apôtres de la liberté se rendent en affluence dans un pays corrompu, pour y réchauffer l'esprit public $^{128}$. Die Propagande war eine Gruppe von etwa sechzig frankophonen Clubbisten aus den umliegenden Départements. Ihre Mitglieder fielen durch eine besondere Kluft, bestehend aus langem Mantel und Säbel, auf. Sie ließen sich lange Schnurrbärte wachsen und trugen stets die rote Mütze. Die Versor-

\footnotetext{
${ }^{127}$ Vgl. Kapitel II.2, Diagramme X-XII.

${ }^{128}$ Les Républicains des Départements de Saône et Loire, et la Côte d'Or, Députés à Strasbourg, par les Sociétés populaires de Châlon sur Saône et Beaune, à leurs Frères de la Société populaire de Beaune, 21 brum. II, in: Livre Bleu, Nr. 60, Bd. 2, S. $169 f$.
} 
gung der Propagande erfolgte auf Kosten der Gemeinde; sie war, gemessen an der Knappheit der Versorgungsguiter, ausgezeichnet. Die Propagande dominierte im Brumaire die Clubsitzungen; überall, wo die Jakobiner öffentlich auftraten, standen ihre Mitglieder im Vordergrund.

Für die lokalen Akteure, die auch in der Zeit der Terreur für Ämter in Frage kommen wollten, war die Beherrschung der französischen Sprache ein Muß. Wer sich den Volksvertretern besonders empfehlen und sich als glühender Jakobiner darstellen wollte, griff zudem die harten Worte gegen die Deutschen, die deutschsprachigen Elsässer und die deutsche Sprache auf. Die unterschiedlichen Wege der lokalen Führer Pierre François Monet und Eulogius Schneider zeigen, wie sich Karrierismus, Loyalitätsfragen und kulturelle $\mathrm{Zu}$ gehörigkeit vermischten.

Die politischen Zielvorstellungen der beiden Protagonisten differierten kaum. Beide waren überzeugte Jakobiner, die sich ideologisch an der Pariser Führung orientierten. Schneider und Monet waren beide Anhänger einer Politik des Schreckens. Schneider hatte sich stets an den radikalsten Pariser Strömungen orientiert, um sich so als lokaler Führer zu empfehlen. Er stellte sich jedoch vor, daß er, einmal an die Spitze gelangt, unabhängig in seinen Entscheidungen sein würde. Monet hingegen war Stratege und Taktiker, der seine Stellung durch Anpassung und Gehorsam gegenüber den sich wandelnden Autoritäten erlangte und erhielt. Wenn es von ihm erwartet wurde, zögerte er nicht, harte Worte zu sprechen. Aber er reagierte mehr als er agierte, und er verstand es, seine politische Existenz durch Dienstbeflissenheit gegenüber seinen Vorgesetzten zu sichern.

Sowohl für Monet als auch für Schneider bedeutete der Beginn des Terrors einen deutlichen Machtzuwachs; beiden gelang es, eine Reihe von wichtigen Ämtern an sich zu ziehen. Monet machte sich als Bürgermeister und auf anderen Posten zum Erfüllungsgehilfen der Politik der Représentants du peuple en mission. Er sorgte für die schnelle und reibungslose Umsetzung ihrer Anweisungen und erlaubte sich in keiner Frage eine eigene Meinung. Auch Schneider diente sich den Repräsentanten an, war aber kein so willenloses Werkzeug wie sein Gegenspieler. Nach seiner Berufung zum Commissaire bei der Revolutionsarmee glaubte er, seine eigenen Vorstellungen von der Schreckenspolitik ins Werk setzen zu können.

Im Frühherbst hatte er sich gebrüstet, jakobinischer zu sein als die Vertreter des Konvents. In seiner Zeitung schrieb er eine Serie von Artikeln unter dem Titel Auch einmal deutsch gesprochen mit den Volksrepräsentanten ${ }^{129}$, welche ausgesprochen kritisch waren. Schneider warf den Repräsentanten Versäumnisse im militärischen Bereich und bei der Assignaten- und Requisitionspolitik vor.

${ }^{129}$ Art. ,Auch einmal Deutsch gesprochen mit den Volksrepräsentanten“, in: Argos, Nr. 40, 1. Okt. 1793, S. 316. 
Hättet ihr euch überall als thätige und unerschrockene Männer gezeigt, so wären die Drachen der Aristokratie und des Feuillantismus unter uns erstickt; so wehten die Nationalfahnen wieder auf den Wällen von Mainz, und der Feind hätte mit Schimpf und Schande abziehen müssen. Aber es verflog ein Monat nach dem anderen, und ihr regtet euch nicht. Doch ich hoffe, die ächten Jakobiner werden nicht schweigen, bis ihr entweder unschuldig und weiß wie der Schnee da steht, oder bis die Larve des schändlichen Moderantismus, des Meuchelmords unsrer Freiheit, von eurer Stirne gerissen ist $^{130}$.

Der Konflikt zwischen Schneider und Monet war also zunächst keine Auseinandersetzung um politische Prinzipien und auch keine kulturelle Auseinandersetzung; die beiden unterschieden sich vor allem in ihrer Bereitschaft zur Loyalität gegenüber den neuen Autoritäten.

Mit der Einrichtung eines Gouvernement révolutionnaire kam das Ende von Schneiders politischer Laufbahn. Am 24. Frimaire (14. Dezember 1793) wurde er und die anderen Kommissare der Revolutionsarmee gefangengenommen angeblich wegen ihres prunkvollen entrées in Straßburg. Am 21. Nivose (10. Januar 1794) ordneten die Repräsentanten Baudot und Lacoste die Internierung von elf weiteren Straßburger Jakobinern an, von denen drei nach Paris und neun nach Dijon verbracht werden sollten. Als Begründung für diese Maßnahme wurde angegeben, daß einige der Verhafteten die Permanenz der Sektionen wiederherstellen wollten, um so einen Aufstand in der Stadt anzetteln zu können. Andere bezeichnete man schlicht als gens suspects et dangereux ${ }^{131}$. Die Verhaftungen wurden von einer weiteren Säuberung der Stadtverwaltung begleitet.

Monet, der seit der Verhaftungswelle von sich behaupten konnte, der wichtigste lokale Führer zu sein, kommentierte die Verhaftung mit den Worten:

C'est ici l'époque où se développe à Strasbourg le complot, qui de crise en crise a continuellement marché de pair avec la conjuration ourdie à Paris pour renverser le gouvernement révolutionnaire et républicain; Voigt, Schneider, Jung, Leorier, Clauer, Breck, Nestlin, Wolff, Clavel, que la société populaire a depuis sagement proscrits de son sein, et tant d'autres qui intriguaient à l'ombre des premiers, étaient d'un coté secondés par de nombreux agens qui se multipliaient et semblaient se reproduire, pendant que les représentans étaient de l'autre avec un petit nombre de républicains que l'on réduisait au silence, sur lesquels l'on provoquait les soupçons et les doutes,

${ }^{130}$ Ibid.

${ }^{131}$ Repr. BAUdOT, LaCOSTE, Arrêté des Représentans du peuple près les Armées du Rhin et de la Moselle, 21 niv. II [Arch. Nat. Paris, AF II 135, doss. 1038, 25]. 
qui n'avaient pour tout appui qu'une conduite révolutionnaire sans tache et la bonté de leur cause. Une faction puissante venait de se former; Schneider en était l'ame. Pour réussir dans ses projets il s'attacha principalement à ravir la confiance du peuple aux représentants et à ceux qui agissaient dans leur sens et leurs principes. [...] Jung, marchant sur ses traces, exhalait en énergumène les féroces imprécations de la rage contre ces représentants ${ }^{132}$.

Es entsprach Monets Vorsichtigkeit, in der Anklage gegen Schneider keine Argumente aus dem Arsenal des Anti-Germanismus zu verwenden. Er stellte die Verhaftung der Schneider und den anderen als gelungener Schlag gegen einen Verschwörungsplan dar. Die Rede, in der Monet mit Schneider abrechnete, war jedoch ein discours sur la conjuration de l'étranger, und so wurde nachträglich die kulturelle Frage in den Loyalitätskonflikt hineingebracht, ohne ihn indes zu dominieren. Schneiders kultureller Hintergrund (und seine kirchliche Vergangenheit) waren lediglich zusätzliche Argumente, die jedoch die Plausibilität seiner Anklage erhöhen sollte. Dazu kam, daß von den elf Verhafteten viele entweder aus Straßburg, aus Deutschland oder anderen Ländern kamen ${ }^{133}$. So schien es nur folgerichtig, daß kurz nach der Verhaftungswelle die deutschen Sitzungen des Clubs und die Verwendung der deutschen Sprache in den Debatten verboten wurden.

Das kulturelle Moment im Konflikt zwischen Monet und Schneider verstärkte sich, als Personen, die zumindest von den frankophonen Jakobinern zu einer „Schneider-Fraktion" gezählt wurden, ihre Stimme zur Verteidigung der Straßburger erhoben:

Ce n'est point peu de chose que de porter ainsi atteinte à la réputation d'une ville entière, où tant de braves gens résident, qui sous en tel point de vue y sont compromis. [...] Si dans nos cités quelques malveillans de ces maudits aristocrates offusquent vos regards, tâchez à les détruire, leur aspect nous est un supplice, mais n'y confondez point tous nos habitans, qui, par leur zèle ardent, peuvent prétendre au témoignage honorable de leurs frères ${ }^{134}$.

Auch der Argos, nach Schneiders Verhaftung von Butenschoen weitergeführt, nahm die Elsässer in Schutz:

Sollte man den Leuten glauben, die aus dem Innern der Republik zu uns kommen; so wäre Strasburg ein zweites Sodom und Gomorra, das nichts bessers verdiente, als durch Feuer vom Himmel verheert und verzehrt zu

\footnotetext{
${ }^{132}$ MONET, Discours sur la conjuration de l'étranger, S. 91.

${ }^{133}$ Die Prozesse der Straßburger Jakobiner vor dem Pariser Revolutionstribunal finden sich in den Archives Nationales [Arch. Nat. Paris, W 343, doss. 662; W 421, doss. 956; W 450, doss. 115; W 476, doss. 324; W 482, doss. 361].

${ }^{134}$ Anonymer Brief an den Club, in: Livre Bleu, Nr. 11, Bd. 2, S. $70 \mathrm{f}$.
} 
werden. Hier soll der Fanatismus in seiner ganzen Scheuslichkeit wohnen, hier sollen höchstens nur drei Patrioten leuchten. Ich habe den Straßburgern nie geschmeichelt, das weiß alle Welt, aber ich müßte ein Schurke sein, wenn ich jetzt nicht laut spräche, da es recht à l'ordre du jour zu sein scheint, alles, was in Strasburg geschieht und aus Strasburg kommt, mit Gift und Galle zu überschütten. Wird etwas Gutes in Strasburg gedacht, so heißt es dumm, wird etwas Gutes in Strasburg gethan, so heißt es deutsch, schlecht, erzwungen. Und gerade dieses nenne ich dumm und abscheulich. [...] Giebt im Innern der Republik irgend eine Stadt nur ein paar Schuhe oder Pantalons, so wundert man sich gleich über ihren treflichen Bürgersinn, in Straßburg können sich die Bürger getrost nackt ausziehen, um ihre Brüder zu kleiden, sie sind Aristokraten, thun alles erzwungen, nie etwas aus gutem Herzen ${ }^{135}$.

Diese frechen Töne wurden durch Angriffe auf Monet und die Propagande ergänzt: In einem Brief aus dem Gefängnis warfen ehemalige Straßburger Jakobiner dem Straßburger Bürgermeister vor, daß er sich stets den herrschenden Meinungen anpasse: On l'a vu singer les ultra-révolutionnaires, et s'entretenir dans son cabinet, plusieurs heures par jour, avec des aristocrates de l'un et de l'autre sexe ${ }^{136}$. Der Propagande warf man ihr ausschweifendes Leben, aber auch ihre ungerechten anti-elsässischen Ressentiments vor: Ils ont mis en délibération la déportation des habitans du Bas-Rhin, parce qu'ils ne parlent pas la langue française ${ }^{137}$. Massé wagte aus dem Gefängnis sogar Angriffe gegen den Stadtkommandanten Dièche. Dieser sei bei einem Angriff auf Kehl so betrunken gewesen, daß er dreimal vom Pferd gefallen sei. Dessen Adjutanten Téterel bezeichnete er als patriote de deux jours und als héros de l'antichambre und empfahl ihm zu lernen, wie man kämpft, denkt, liest und schreibt ${ }^{138}$. Auch Butenschoen und Schneider wagten es nach ihrer Verhaftung, die Repräsentanten anzugreifen. Der Argos, der nicht verboten wurde, war weiterhin ihr Sprachrohr. Butenschoen berichtete: Neulich stieg in der Volksgesellschaft ein Mensch auf die Tribüne und sprach im sichtbaren Rausche: Auf meinen Befehl ist Schneider, die Seele der Strasburger Patrioten, an den Schandpfahl gestellt worden! Das Frankenvolk ist edel und gerecht, dieser berauschte Mensch war also kein Repräsentant des Frankenvolkes ${ }^{139}$. Schneider rühmte sich noch im Gefängnis seines Widerstandes gegen die Propagande: Wisse, daß die Haupt-

\footnotetext{
${ }^{135}$ Art. „Strasburg ist verläumdet.“, in: Argos, Nr. 1, 4 niv. II.

${ }^{136}$ MASSE, JUNG, VOGT, WOLFF, Histoire de la propagande et des miracles qu'elle a faits à Strasbourg pendant son séjour dans cette commune, dans le mois de frimaire de la présente année, 24 pluv. II, in: Livre Bleu, Pièces à l'appui Nr. 101, Bd. 1, S. 155.

${ }^{137}$ Ibid. S. 157.

${ }^{138}$ Le Sans-culotte MASSE au Général Dièche, commandant de la division de la place de Strasbourg, 15 pluv. II, in: Livre Bleu, Nr. 115, Bd. 2, S. 231.

${ }^{139}$ Art. „So spricht kein Volksrepräsentant“, in: Argos, Nr. 1, 4 nivose II.
} 
ursache, warum gewisse sogenannte Propagandisten, die, ich weiß nicht von wem, nach Strasburg geschickt waren, mir einen unversöhnlichen Haß schwuren, darinn lag, weil ich mich ihren tollen und menschenfeindlichen Mozionen ernsthaft widersetzte ${ }^{140}$.

Die Auseinandersetzung zwischen zwei unterschiedlich loyalen Karrieristen erhielt also im Nachhinein einen kulturellen Beigeschmack. Politik und kulturelle Identität griffen ineinander. Mit der Ausbreitung von Verschwörungstheorien wurde die Definition, wer zum Kreis der Jakobiner gehörte, enger; der Kreis der Feinde weitete sich aus. Die Vorstellung von einer frankophonen Einheitskultur begann, das jakobinische Selbstverständnis zu bestimmen. Die Bereitschaft, Gewalt zur Ausschaltung der durch kulturelle Unterschiedlichkeit Gegner einzusetzen, war nun voll entwickelt. Wie erklärt sich diese Weiterentwicklung der jakobinischen Selbst- und Feindbilder? Es war wiederum das Zusammenspiel von inneren und äußeren Faktoren, welche den ideologischen Wandel vorantrieben. Wieder gab es zwei Gruppen, die sich auf der lokalen politischen Bühne bekämpften. Wieder überlagerten sich politische Differenzen und hergebrachte kulturelle Identitäten. Wieder nutzten die Rivalen Argumente aus dem Kontext nationaler Politik zur Legitimation ihres Anspruches auf die Macht. Wieder wurde ihr Zwist durch den Eingriff der Zentralgewalt entschieden. Die Antipathie gegen die Germanophonen mußte den französischsprachigen Jakobinern allerdings nicht von außen aufgezwungen werden. Viele von ihnen kannten noch die alten deutsch-französischen Auseinandersetzungen; sie alle sahen die Deutschen als ihren hauptsächlichen Feind an. An eine Verschwörung der Germanophonen zu glauben, war für sie nur noch ein kleiner Schritt.

\section{Jakobinismus als Religion}

In den ersten Wochen der Terreur hatte sich das jakobinische Selbstverständnis gewandelt; die Jakobiner verstanden sich ab dem Herbst 1793 vor allem als entschlossene Gegner einer imaginierten anti-republikanischen Verschwörung. Ihr Selbstbild war darüber hinaus durch die Mittel geprägt, welche im Kampf gegen die Konspiration einzusetzen waren. Die Einführung des Kultes der Vernunft erweiterte diese Selbstdefinition ex negativo. Die Vernunftsreligion berücksichtigte die verschiedenen Feindbilder, vor allem aber formulierte sie

${ }^{140}$ Art. „Eulogius Schneider, ehemals öffentlicher Ankläger beim Criminal-Gerichte des Niederrheinischen Departements, jetzt im Arresthause, genannt die Abtei, zu Paris. An Robespierre den Alten, Stellvertreter der fränkischen Nation“, in: Argos, Nr. 24, 4 ventose II. 
ein Heilsversprechen. Nach dem erbitterten Kampf, so lautete dieses, werde das Reich der Freiheit, Gleichheit und Brüderlichkeit anbrechen. Die Jakobiner verstanden sich als Apostel einer neuen Religion und als Verkünder von Wahrheiten, die durch das Höchste Wesen verbürgt waren ${ }^{141}$. Durch die Konstruktion einer metaphysischen Grundlage wurde der Glaube an die eigene Überlegenheit und auch die Intoleranz gegen Andersdenkende noch gesteigert. Kirchenschließungen, Verbote von Gottesdiensten und eine Abschwörungskampagne waren die Folge. Prosélytes de Moïse, de Calvin, de Luther et de Ro$\mathrm{me}^{142}$ wurden jetzt zu Opfern der Verfolgung ${ }^{143}$. Im folgenden werden sowohl die wachsende Ablehnung der traditionellen Religionsgemeinschaften als auch die Kampagne für den jakobinischen Kult beschrieben und als Bestandteil der Radikalisierung analysiert.

\section{Dechristianisierung und Kult der Vernunft}

Die lokale Vorgeschichte der jakobinischen Religionspolitik des Winters 1793/94 wurde bereits ausführlich beschrieben: Die Anfeindungen gegen katholische Priester, die den Eid verweigerten, hatten im Sommer 1790 begonnen. Sie erreichten 1792 einen ersten Höhepunkt, als die konstitutionelle Kirche zum Zankapfel zwischen Gemäßigten und Jakobinern wurde. Das Feindbild des Priesters weitete sich im Laufe der Zeit aus. Im Herbst 1793 wurden auch die protestantischen Priester angegriffen. Zwar war im Argos zunächst festgestellt worden, daß Republikanismus und Protestantismus Eines sind ${ }^{144}$, doch wenig später wurde im selben Blatt den Straßburger Protestanten vorgeworfen, nicht am Kern ihres Glaubens festzuhalten, sondern die Religion als Rechtfertigung ihres Strebens nach Macht und Geld zu benutzen ${ }^{145}$. Der Vorwurf der Verweltlichung, den die Jakobiner ursprünglich der katholischen Kirche gemacht hatten, wurde also auch auf die Protestanten übertragen.

141 Vgl. Claude LEFORT, La Révolution comme religion nouvelle, in: François FURET, Mona OzOUf (Hg.), The French Revolution and the Creation of Modern Political Culture, Bd. 3: The Transformation of Political Culture 1789-1848, Oxford u.a. 1989, S. 391-398.

${ }^{142}$ Pierre-François MONET, Au peuple! Strasbourg, le 29 Brumaire de l'an II, le maire de Strasbourg, Strasbourg 1793, zit. nach REUSS, La constitution civile, S. 230f.

${ }^{143}$ Zum Religionsterror: Jean BERNET, Les limites de la déchristianisation de l'an II éclairées par le retour au culte de l'an III: L'exemple du district de Compiègne, in: AHRF 70 (1998) S. 285-299; REUSS, La Constitution civile; Michel VOVELLE, La Révolution contre l'église. De la raison à l'être suprême, Bruxelles 1988; DERS., Religion et Révoution. La déchristianisation de l'an II, Paris 1976; DERS, The Adventures of Reason, or From Reason to the Supreme Beeing, in: Colin JONES (Hg.), Rewriting the French Revolution, Oxford 1991, S. $132-150$.

${ }_{144}$ Art. „Über den Zustand des Religionswesens im Niederrheinischen Departement“, in: Argos, Nr. 29, 5. Sept. 1793.

${ }^{145}$ Art. „Über den Zustand des Religionswesens im Niederrheinischen Departement (suite)“, in: Argos, Nr. 31, 10. Sept. 1793. 
Die überhandnehmende, wahnhafte Angst vor Verschwörungen führte zu einer weiteren Verschärfung des Feindbilds vom Priester, der jetzt als Teil der Konspiration gegen die Republik angesehen wurde. In einem Beschlu 3 der Repräsentanten Goujon und Hentz, der allerdings aus dem Sommer des Jahres 1794 stammt, wird die Art und Weise deutlich, in der die Priester in das Verschwörungsszenario eingefügt wurden. Sie wurden beschuldigt, die Bürger an den Sonntagen des alten Kalenders unter dem Vorwand des Gottesdienstes vom Arbeiten abzuhalten und so die Einbringung der Ernte zu verhindern. Außerdem wurde ihnen die Entwertung der Assignaten und der Einfluß des Feindes im Elsaß angelastet:

Leurs vils asservissemens envers les riches du pays, dont ils sont les esclaves, à cause de l'argent qu'ils en reçoivent, les portent à favoriser la sortie du numéraire, à colporter la correspondance qui subsiste entre les émigrés et les aristocrates de l'intérieur sur une frontière où les malveillans abondent. [...] Le résultat de leurs mancuvres dans ces Départemens, est une ignorance totale des lois de la liberté, le mépris de la monnoie républicaine porté à un tel dégré, que les propriétaires, dans quelques endroits, préfêrent laisser périr les productions de la terre à en faire l'échange contre cette monnoie ${ }^{146}$.

Je weiter sich die Terreur ausprägte, desto gräßlicher wurden die Verbrechen, die man den Priestern zuschrieb:

Le crime étoit donc au point que les prêtres ont inspiré à un malheureux fanatisé que s'il égorgeoit sa femme et mangeoit les testicules (une partie du corps) d'un enfant, dieu le rendroit invisible et qu'alors favorisé de ce don il pourroit faire tout ce qu'il voudroit; eh bien, frères et amis, ce fanatisé a voulu égorgé sa femme qui étoit enceinte et qu'on au eu toute la peine à arracher à sa fureur inspirée par les prêtres, les testicules d'un enfant ont été mangées, nous avons trouvé le coupable chargé de fers dans la prison de la commune d'Hirsingue ${ }^{147}$.

Die von solcher Greuelpropaganda begleitete Dechristianisierungspolitik folgte keineswegs Weisungen aus Paris ${ }^{148}$. Es waren zunächst die Repräsentanten Dumont, Fouché und Chaumette, welche auf ihrer Mission in den südli-

${ }^{146}$ Repr. Goujon, Hentz, Beschluß vom 4 therm. II [Arch. Nat. Paris, AF II 135, doss. $1044,14]$.

${ }^{147}$ Brief DiÈchE an die Société populaire, o.D., in: Livre Bleu, Nr. 48, Bd. 2, S. 146.

${ }^{148}$ Für eine ausführlichere Behandlung des Kultes der Vernunft in Straßburg s. Daniel SCHONPFLUG, Das Münster unter dem bonnet rouge. Dechristianisierung und Kult der Vernunft in Straßburg (1793-1794). Zur Eigenständigkeit einer lokalen Politik der Symbole, in: Francia 25/2 (1998) S. 105-129. 
chen Départements ${ }^{149}$ Aktionen zur Abschaffung der traditionellen Kirche durchführten. Ihnen folgte das von Pariser Sektionen, Kommune und Département organisierte Fest der Vernunft, das am 20. Brumaire (10. November 1793) in Notre-Dame stattfand. Dann begann die „Dechristianisierungswelle“ über Frankreich zu rollen; in zwei Dritteln der französischen Départements faßte die Erneuerungsbewegung Fuß ${ }^{150}$.

Der Konvent verhielt sich neutral. Von wenigen Ausnahmen abgesehen, waren die Deputierten nicht bereit, eine solche Politik mitzutragen oder sich gar an ihre Spitze zu stellen. An den Feierlichkeiten in der ci-devant cathédrale de Notre Dame beteiligte sich nur ein Teil der Abgeordneten. Weder zur Dechristianisierung noch zur Einrichtung des Kults der Vernunft gab es einen Beschluß des Konvents. Die Dechristianisierung blieb Sache der Volksvertreter auf Mission und der Kommunen, die durch Volksbeschluß den katholischen Staatskult abschafften und die Priester zur Abdankung zu bewegen versuchten. Der Konvent stützte diese Politik nur durch einige Regelungen, so zum Beispiel durch das Gesetz vom 23. Brumaire (13. November 1793), das den munizipalen Verwaltungen auftrug, die Abschwörungen von Priestern amtlich zu bestätigen, und das Gesetz vom 25 . Brumaire (25. November 1793), das den dechristianisierten Gemeinden zugestand, Kirchengebäude zur öffentlichen Nutzung zu verstaatlichen ${ }^{151}$. Gleichzeitig erinnerte die nationale Vertretung jedoch immer wieder an den Grundsatz der Religionsfreiheit.

Diese ambivalente Haltung des Konvents hatte zur Folge, daß die Politik in den Départements vielfältig war. Im Elsaß waren es die Kommissäre Milhaud und Guyardin, welche eine neue Religionspolitik ins Leben riefen. Ihr Beschluß vom 17. Brumaire des Jahres II (7. November 1793) war der Anfang von Dechristianisierung und Vernunftkult im Osten. Darin prangerten sie erneut die Priester an und forderten alle Menschen auf, sich autour de l'autel de la nature ${ }^{152} \mathrm{zu}$ versammeln und les principes éternels de la morale universel$l e^{153}$ als einzige Religion anzuerkennen. Um dies zu erreichen, wurde der Gottesdienst nur noch in den dafür vorgesehenen Gebäuden zugelassen. Die äußeren Zeichen der Religion sollten von Straßen und Plätzen verschwinden, die in den Kirchen aufbewahrten wertvollen Kultgegenstände eingesammelt werden. Den Priestern wurde nahegelegt, durch Heiraten und durch den Widerruf ihres Gelübdes zu apôtres de l'humanité zu werden. Diejenigen von ihnen, die weiterhin im alten Stil ihr Amt versahen, sollten ins Landesinnere deportiert werden. Der Beschluß enthielt wohlgemerkt kein explizites Verbot

\footnotetext{
${ }^{149}$ Alphonse AULARD, Le Culte de la Raison et le Culte de l'Être suprême (1793-1794). Essai historique, Paris 1892 (Neuaufl. Aalen 1975), S. 24-42.

${ }^{150}$ VOVELLE, Religion et Révolution, S. 15.

${ }^{151}$ AULARD, Le Culte de la Raison, S. 60.

${ }^{152}$ Repr. Milhaud, GUYARdin, Beschluß vom 17. Brum II [Arch. Nat. Paris, AF II 247, Doss. 2110, 27].

${ }^{153}$ Ibid.
} 
der traditionellen Religionen, sondern lediglich ein Verbot der Darstellung derselben im öffentlichen Raum; die symbolpolitische Maßnahme griff also in diesem Fall einer realpolitischen vor. Die Einführung eines neuen Kultes wurde in dem Dekret durch die Nennung des autel de la nature angedeutet. Gleichzeitig wurde mit der Revolutionsjustiz, verkörpert durch eine Commission révolutionnaire, gedroht, um keinen Zweifel an der Entschlossenheit der Représentans du peuple aufkommen zu lassen.

Die örtliche Verwaltung reagierte prompt. Zwei Tage nach der Anordnung von Milhaud und Guyardin verbot die Commission provisoire du département das Läuten der Kirchenglocken ${ }^{154}$; der Jakobinerclub wurde beauftragt, eine Kommission zusammenzustellen, welche die Entfernung der Zeichen überwachen sollte ${ }^{155}$. Am selben Tag wies die provisorische Départementsverwaltung die untergeordneten Stellen an, Kartenspiele aus dem Verkehr zu ziehen, auf denen noch die Zeichen der alten Herrschaft abgebildet waren ${ }^{156}$. Die lokale Forschung des 19. Jahrhunderts - allen voran Rodolphe Reuss - hat den reaktiven Charakter dieser Maßnahmen betont, um den Repräsentanten die volle Verantwortung für die kirchenfeindlichen Inititativen zu geben ${ }^{157}$. Doch die Politik der Commission provisoire war schon vor diesem Termin den traditionellen Kirchen nicht wohlgesonnen. Am 16. Brumaire (6. November 1793) hatte sie die Umbenennung einiger Straßen angeordnet und darauf beharrt de détruire les aliments de la sottise ou de la perversité und de les remplacer par des signes qui annoncent l'élan du peuple vers la liberté ${ }^{158}$. Zuvor hatte die Kommission das Einsammeln aller wertvollen Gefäße aus den Kirchen angeordnet. Am 14. Brumaire (4. November) war die Requisition von Kirchen zu militärischen Zwecken angeordnet worden ${ }^{159}$. Bevor Paris von der Welle der Dechristianisierung ergriffen wurde und vor einer expliziten Anordnung der Représentants du peuple, gab es in Straßburg also bereits Ansätze einer neuen Religionspolitik, die jedoch zunächst folgenlos blieb.

Unter dem verstärkten Druck im Brumaire war es vor allem der Straßburger Bürgermeister Monet, der sich zum lokalen Organisator der Dechristianisierung berufen fühlte. Monet und die Propagande bildeten eine Plattform für die Verbreitung des Vernunftkultes in Straßburg. Sie waren es, die sich den Vor-

${ }^{154}$ Registre de la Commission provisoire du département, 19 brum. II [Arch. Dépt. Bas-Rhin, 1 L 531, Nr. 33101].

155 Ibid. Nr. 33094.

156 Ibid. Nr. 33113.

${ }^{157}$ Rodolphe REUSS, La Cathédrale de Strasbourg pendant la Révolution. Etudes sur l'histoire politique et réligieuse de l'Alsace, Paris 1888, S. 416. Reuss gibt an, daß die Commission provisoire zwei Tage nach der Anordnung der Représentants du peuple die Ausübung jedweder Religion pendant la guerre verboten hätte. Diese Anordnung ist in den Registern nicht zu finden.

${ }^{158}$ Registre de la Commission provisoire du département, 16 brum. II, [Arch. Dépt. BasRhin, 1 L 531, Nr. 32987].

${ }^{159}$ REUSS, La Constitution civile, Bd. 2, S. 216. Vgl. auch HEITZ, Les sociétés politiques, S. 302. 
satz der Repräsentanten Milhaud und Guyardin de rallier tous les hommes autour de l'autel de la nature zu eigen machten. Der Kult der Vernunft wurde als demokratischer Kult verstanden, und die Straßburger Jakobiner verzichteten nicht darauf, seine Einführung durch einen „Volksbeschluß“ zu legitimieren. Am 27. Brumaire des Jahres II (17. November 1793) wurde in der Kathedrale eine Versammlung abgehalten, bei der Vertreter verschiedener Jakobinerclubs des Elsaß, die Propagande révolutionnaire, die Représentants du peuple Lacoste und Mallarmé, die Stadtverwaltung und Straßburger Bürger anwesend waren. Die Veranstaltung wurde von den Reden der Propagande bestimmt, die bei dieser Gelegenheit ihren ersten öffentlichen Auftritt hatte. Ils [die Redner der Propagande] ont montré le prêtre toujours d'accord avec le tyran pour enchaîner le genre humain et le premier abusant du nom du ciel pour empêcher l'homme d'user des droits de la nature ${ }^{160}$.

Im Anschluß wurde gefordert que le peuple énonçat son vœu sur les prêtres $^{161}$. Die Befragung erfolgte in Französisch und Deutsch und die acclamations générales der Versammelten galten als ausreichender Beweis für den Wunsch der Stadt, keine der traditionellen Kirchen mehr anzuerkennen. Dann verkündete der Bürgermeister Monet den Beschluß des Stadtrates, den kommenden Dekadi mit einem Fest zu Ehren der Vernunft zu feiern ${ }^{162}$ - die begeisterten acclamations der Versammelten wurden wiederum als hinreichender Ausdruck der Zustimmung zur déchristianisation interpretiert. Am 1. Frimaire des Jahres II (21. November) verbot die Commission provisoire du Département daher alle herkömmlichen Formen des Kultes, deren Ziel es sei [de] propager l'erreur et de rechef vouloir asservir un peuple libre au despotisme le plus monstrueux ${ }^{163}$.

Drei Tage blieben der Stadtverwaltung, der Propagande und dem örtlichen Jakobinerclub, um die angekündigte Feier zu Ehren der Vernunft vorzubereiten. Über die genaue Verteilung der Aufgaben ist wenig überliefert. Sicher ist, daß die Stadtverwaltung die Kosten für die Veranstaltung trug. Am Vortag des Festes veröffentlichte der Bürgermeister Monet ein Plakat, in dem es hieß:

Un nouveau jour va luire sur notre patrie; déjà la loi nous réunit tous au jour du repos qui est fixé à chaque décade. Ce jour sera respecté à l'avenir par le citoyen. Le bâtiment connu jusqu'içi sous le nom de Cathédrale et qui le sera désormais sous celui de Temple de la Raison, est destiné au culte

${ }^{160}$ Procès-verbal de l'Assemblée générale des Autorités constituées, de la Société Populaire et du Peuple de Strasbourg et des membres des Sociétés populaires des Départements voisins, réunis au Temple de la Raison, le 27 jour de l'an 2 de la République une et indivisible, Strasbourg 1793, S. 4f. [Bibl. Nat. Univ. Str., M 6458].

${ }^{161}$ Ibid. S. 6.

${ }^{162}$ Registres du Corps municipal de Strasbourg, 27 brum. II (Art. 2069) [Arch. Mun. Str.].

${ }^{163}$ Auszug aus den Registern der Départementsverwaltung vom 1. Frim. II [Arch. Mun. Str., Fonds $5 / 15,91]$. 
simple que rendront aux vertus sociales et à la liberté les hommes purs et dégagés des préjugés des siècles de barbarie. [...] Les prêtres bons citoyens [...] qui n'ont pas éteint dans leur âme les sentiments de la moralité, viendront ce jour à la tribune du nouveau temple rendre hommage à la vérité et à la nature ${ }^{164}$.

Am Morgen des 30. Brumaire des Jahres II (20. November 1793) nahmen die Straßburger Festlichkeiten zu Ehren der Vernunft ihren Anfang ${ }^{165}$. Der Festzug versammelte sich am Sitzungssaal des Straßburger Jakobinerclubs. Dort trafen sich nicht nur die Clubmitglieder, sondern auch Bürgerinnen aus den Reihen der Amies de la République, die sich im weißen Jungfrauengewand und mit der Jakobinermütze auf dem Kopf einfanden - ein Kostüm, das ihren natürlichen Charme stärker zur Wirkung brachte als die geborgten Ornamente eines verderbenden Luxus ${ }^{166}$.

Um neun Uhr setzte sich die Versammlung in Bewegung. Dem Zug wurde die Büste Marats vorausgetragen, der als Opfer seiner Überzeugungen zum Märtyrer ${ }^{167}$ des Kultes der Vernunft geworden war. Darüber hinaus trugen die Jakobiner Rutenbündel, Symbole der Einheit, und Piken als Zeichen der Wehrhaftigkeit des französischen Volkes mit sich. Die Bürgerinnen führten den Zug an, ihnen folgten die Clubmitglieder, in deren Reihen sich Bürger de tous les rangs ${ }^{168}$ gemischt hatten. Der Zug erreichte zunächst die Unterkunft der Représentants du peuple. Der Repräsentant Baudot schloß sich der Menge an. Anschließend stattete man der Maison commune einen Besuch ab; unter den Klängen einer Marschmusik reihten sich die Mitglieder der militärischen und der Zivilverwaltung ein. Dann zog man weiter zum Temple de la Raison, wie das Straßburger Münster nun getauft wurde.

Dieses hatte sich in den drei Tagen seit dem „Volksbeschluß“ sehr verändert. Über dem Hauptportal prangte ein Holzschild mit der Aufschrift $\mathrm{La}$ lumière après les ténèbres ${ }^{169}$. Der Gegensatz von Dunkelheit und Licht, der in allen Festveranstaltungen der Revolution eine wichtige Rolle spielte, versinn-

\footnotetext{
${ }^{164}$ MONET, Au peuple!

${ }^{165}$ Es liegen, neben dem offiziellen Festprotokoll, vier Zeitungsberichte über das Fest vor: Art. „Der heilige Dekadi“", in: Argos, Nr. 62, 2 frim. II; Art. „Straßburg, $1^{\text {er }}$ Frimaire“, in: Weltbote, Nr. 275, $1^{\text {er }}$ frim. II; Art. „Über Mißbräuche in Straßburg“, in: Weltbote, Nr. 276, 2 frim. II; Art. „Straßburg, vom 30 Brumaire“, in: Straßburgische Zeitung, Nr. 273, 1 frim II. Ein weiterer Bericht findet sich in J. FRIESE, Neue vaterländische Geschichte der Stadt Straßburg und des ehemaligen Elsasses von den ältesten Zeiten bis auf das Jahr 1791, Bd. 6, Straßburg 1801, S. 361.

${ }^{166}$ Description de la fête de la raison, célébrée pour la première fois à Strasbourg, Strasbourg 1793, S. 2f. [Bibl. Nat. Univ. Str., M 121 516].

${ }^{167}$ Zum Märtyrerkult der Revolution: Antoine de BAËCQUE, Le corps de l'histoire. Métaphores et politique (1770-1800), Paris 1993, S. 343-374.

${ }^{168}$ Description de la fête de la raison, S. 3.

${ }^{169}$ Ibid. S. 4.
} 
bildlichte in diesem Fall die Grundidee des Vernunftkultes: die Bewegung vom Ende zu einem neuen Anfang, vom Zeitalter des Aberglaubens zur Ära der Vernunft. Im Inneren des Tempels war das Programm der Reinigung von den Zeichen des Alten mit besonderer Gründlichkeit vollzogen worden. $\mathrm{Ce}$ temple avoit été pendant quinze (!) siècles le théâtre de l'imposture. A la voix de la Philosophie il fut purifié en trois jours de tous les ornemens ridicules qui servoient aux cérémonies du fanatisme. On ne voyoit plus la moindre trace de la superstition ${ }^{170}$. Die Überdachung der Kanzel, die als surchargé des attributs de la vanite ${ }^{171}$ empfunden wurde, war entfernt worden. Der Argos jubelte: Aus dem Tempel der Vernunft waren alle Spiegelfechtereien verschwunden ${ }^{172}$.

An die Stelle der christlichen Symbolik trat eine neue Bildersprache. Zunächst hatte man den Altar durch einen Autel de la patrie ersetzt, der in der Mitte des Hauptschiffes stand. Um ihn herum waren nach der Art eines Amphitheaters aufsteigende Sitzreihen gruppiert; zu seiner Rechten stand eine Rednertribüne. Die Wände waren mit Trikoloren geschmückt. Das Protokoll des Tages wies auf die simplicité dieser Verzierungen hin, die im Gegensatz zur Überladenheit des alten Kultes stehe. Links und rechts von der Rednertribüne hingen zwei Fahnen, die mit Sprüchen versehen waren: Le trône et l'autel avoient asservi les hommes und la raison et la force leur ont rendu leurs droits!

Den Höhepunkt der symbolischen Inszenierung stellte das Monument pour la Nature dar, das im Allerheiligsten errichtet worden war ${ }^{173}$. Der Berg, Allegorie der jakobinischen Bewegung, stand im Zentrum der Anordnung. Er war aus rauhem Gestein gefügt; einige der Steine schienen sich gerade erst vom Gipfel gelöst zu haben; aus seinem Inneren schlugen Blitze und Funken hervor. Die Montagne stellte sich selbst als Vulkankegel dar, der sich über die Umgebung erhob und der bereit war, seine Feinde mit Glut zu versengen. Der jakobinische Berg war Natur, damit Teil einer gegebenen Ordnung und gleichzeitig Symbol gewaltsamen Wandels. Er glich nicht einem vor Jahrtausenden erstarten Felsmassiv, sondern einem lebendigen Wesen, in dessen Innerem verborgene Energien schlummerten: On voyoit que quelques catastrophes terribles s'étoient nouvellement passées dans son $\operatorname{sein}^{174}$. Der Jakobinismus stili-

${ }^{170}$ Ibid.

${ }^{171}$ Ibid. S. 6.

${ }^{172}$ Art. „Der heilige Dekadi“, in: Argos, Nr. 62, 2 frim. II.

${ }^{173}$ Das Monument war von drei Handwerkern, dem Maler Heim, dem Graveur Guérin und dem Tischler Strohé hergestellt worden. Es kostete die Kommune 1340 livres, die aus einem Sonderfonds beglichen wurden. Registres du Corps municipal, 24 niv. II (Art. 2489), [Arch. Mun. Str.].

${ }^{174}$ Dieses und die folgenden Zitate, die das Monument betreffen, aus: Description de la fête de la raison, S. $4 \mathrm{f}$. 
sierte die Revolution zum Naturereignis, die der Erdoberfläche ein neues Gesicht gab ${ }^{175}$.

Auf der Spitze des Berges standen die Statuen der Freiheit und der Natur, welche die obersten Werte des Vernunftkultes in Straßburg darstellten. Mona Ozouf hat die große Bedeutung von Natur und Natürlichkeit in den Festen der Revolution analysiert. Sie beschreibt den Wandel von den unter freiem Himmel stattfindenden Festen der ersten Jahre der Revolution bis zu den Fêtes de la Raison. Der Festplatz im Grünen, außerhalb der Stadt, stehe für einen ,espace sans mémoire", der den Rahmen für eine Rückführung der Gesellschaft in ihren Naturzustand biete. Feste innerhalb der Stadt wollten diesen Rückhalt in einer natürlichen Ordnung keineswegs aufgeben. Doch mußten sie eine neue Form finden, die Natürlichkeit zu erfassen. Dieser Versuch erkläre den hohen Stellenwert der Naturgöttin im Vernunftkult ${ }^{176}$. Durch ein Rutenbündel wurde darüber hinaus an die Bedeutung der Einheit erinnert.

Die Selbstdarstellung der Montagne wurde komplettiert durch die Allegorien eines dreifachen Sieges: Erstens des Sieges über den Despotismus, symbolisiert durch die zertretenen Szepter und durch einen Dolch, Zeichen der Intrige, der von monstres à face humaine, des reptiles à demi ensevelis sous les éclats des rochers davongetragen wurde; zweitens des Sieges über den Aberglauben, dargestellt durch Priester aller Konfessionen, die noch in ihren alten Streitigkeiten befangen waren; unter ihnen fehlte nicht derjenige, der couvert d'un costume religieux cachant la perversité de son âme sous les dehors de la pénitence et cherchant à séduire l'innocence d'une jeune vierge qu'il vouloit corrompre; und drittens des Sieges über die Gemäßigten, versinnbildlicht durch den Sumpf am Fuße des Berges d'où sembloient s'élever des exhalaisons impures; on y remarquoit deux autres monstres au visage abbattu, à l'oil étincellant, qui jettoient des regards terribles vers le sommet de la montagne, comme pour l'accuser de leur malheur. L'un d'eux portoit dans ses mains une couronne teinte de sang, l'autre cachoit un livre ouvert où on lisoit à travers ses doigts des mensonges et des horreurs. Selbstverständnis und Feindbilder des Jakobinismus waren wohl selten sinnfälliger dargestellt worden, als in jenem Monument für die Natur.

Der Festzug wurde, als er in der Kathedrale eintraf, von einer Orchestermusik begrüßt. Dann ging die Versammlung zum Gesang über. Die Hymne à la Nature pries die Natur als Mutter des Universums:

Mère de l'Univers, éternelle Nature!/Le Peuple reconnaît ton pouvoir immortel;/Sur les pompeux débris de l'antique imposture/Ses mains relèvent

${ }^{175}$ Jörn von der THÜSEN, „Die Lava der Revolution fliesst majestätisch“. Vulkanische Metaphorik zur Zeit der Französischen Revolution, in: Francia 23/2 (1996) S. 113-143, bes. S. $121 \mathrm{ff}$.

${ }^{176}$ Mona Ozouf, La fête révolutionnaire 1789-99, Paris 1976, S. 150 f. 
ton autel./Par ton culte fleurit la vertu, le génie,/Et l'homme n'est heureux que par tes douces lois,/Conduit par la douleur au terme de la vie/ll renait encore à ta voix ${ }^{177}$.

In weiteren Hymnen erklang das Lob der Freiheit, der Vernunft und der Natur, der Moral und schließlich des Höchsten Wesens, des Gottes der Revolution, der Natur und Menschen nach vernünftigen Gesetzen geschaffen hatte.

In den Reden des Bürgermeisters, des Accusateur public, des Représentant du peuple wurde das im Monument élevé pour la Nature dargestellte Weltbild im Predigtton erklärt. Gleichzeitig wurde auch das Höchste Wesen vorgestellt, das im Monument keinerlei Abbildung gefunden hatte:

Peuple, sache enfin que ce n'est pas par des prières que l'on peut honorer l'être suprême; sache encore que tu l'offenses en le priant. L'être souverainement juste et bon; l'être qui prévoit tes besoins ne veut pas être prié pour t'accorder ce qu'il te faut. Cesses de comparer Dieu à un juge de l'ancien régime qu'il fallait solliciter pour gagner un procès, et sois bien convaincu que malgré toutes tes prières et tes prêtres tu n'obtiendras que ce qui t'appartient dans l'ordre immuable de la nature ${ }^{178}$.

Die dreistündige Feier wurde abgeschlossen durch weitere Zeremonien der Reinigung: Zahlreiche katholische Priester schworen offentlich ihrem Glauben $\mathrm{ab}^{179}$; dies waren die ersten von den insgesamt etwa hundert Abschwörungen, die im Elsaß stattfanden ${ }^{180}$. Vor dem Altar wurden Reliquienknochen und parchemins gothiques verbrannt. Nach dem Ende der Veranstaltung wurde auf dem Platz vor dem Münster, inzwischen Place de la responsabilité, ein Scheiterhaufen errichtet. Dort wurden fünfzehn Wagenladungen mit Dokumenten aus dem Bischofsamt und die Bilder von Königen und geistlichen Würdenträgern dem Feuer übergeben. [Ils] purifièrent par cet autodafé une athmosphère qu'ils avaient souillée pendant leur vie ${ }^{181}$.

${ }^{177}$ Culte de la Raison. Hymne à la Nature, o. O. u. J., S. 1 [Bibl. Nat. Univ. Str., M 5656].

${ }^{178}$ Discours prononcé dans le Temple de la Raison à Strasbourg, le 30 Brumaire, $2^{\text {eme }}$ année de la République française une et indivisible. Jour auquel on a célébré la Fête de la Raison, par le Citoyen Boy, Strasbourg 1793, S. 10f. [Bibl. Nat. Univ. Str., M 5510].

179 Beispiele für die schriftlich niedergelegte Schwüre in: Schriftstück ohne Titel, o. D. [Arch. Mun. Str., Fonds, 5/15, 431]; sowie in: Pierre-François MONET, Die Priester wollen Menschen werden, Straßburg o. D. [Bibl. Nat. Univ. Str., M 106 671]. Initiativen zur statistischen Erfassung der Abschwörungen: Délibération du Directoire du District de Strasbourg, 13 flor. II, Strasbourg 1794 [Bibl. Nat. Univ. Str., M 188 777, 21].

${ }^{180}$ VOVELLE, La Révolution contre l'Eglise, S. 280.

${ }^{181}$ Description de la fête de la raison, S. 14. Ein Überblick über die Deprêtrisationsbewegung findet sich in: Atlas de la Révolution française, Bd. 9: Religion, hg. von Claude LANGLOIS, Timothy TACKETT, Michel VOVELLE, Paris 1996, S. $42 \mathrm{ff}$. 
Es gab auch Ketzer der jakobinischen Religion. Es waren die letzten Mitstreiter von Eulogius Schneider, welche zwar die feindliche Haltung gegenüber den Priestern teilten, aber dennoch an wichtigen Glaubenssätzen der alten Religion festhielten. Als einer der Führer der Propagande, Delâtre, im Club eine Rede hielt, in der er Jesus als Scharlatan bezeichnete, schwangen sich Jung und Butenschoen, beide enge Vertraute Schneiders, zu einer Verteidigung des Sansculotten Jesus auf ${ }^{182}$. Diese wiederholten sie auch schriftlich, wobei sie Delâtre persönlich angriffen:

Ein junger Geck, der darauf trotzt à la hauteur der Revolution zu sein! [...] Ich einfältiger Sansculotte sage also kein Wort weiter, als daß Jesus immer das Muster meines Lebens sein soll, und daß ich stolz darauf bin, nach seinem Beispiele Wahrheit zu reden, und gerade zu handeln bis in den Tod. [...] Ich [...] bekenne hierdurch, daß ich von dem grossen Charlatan Jesus Christus unendlich mehr gelernt habe, als von dem unverschämten jungen Menschen, der ihn zu höhnen wagt. Ha! Das muß eine kleine, niederträchtige Seele sein, die über den besten, ehrwürdigsten aller Menschen spotten kann! Den Buben hätte man in der Wiege ersticken sollen: denn er ist zu allem, was gut, schön und edel ist, schlechterdings verdorben ${ }^{183}$.

Bereits vorher war im Argos, höchstwahrscheinlich von Schneiders Nachfolger Butenschoen, ein Artikel lanciert worden, in dem er die Religion ihrem Wesen nach verteidigte:

Ich glaube vielmehr, und die Erfahrung aller Zeiten bestätigt es, daß, so lange Menschen Menschen sind, sie durch zweckmäßige Religionsausübungen zur Erfüllung ihrer Pflichten ermuntert und angehalten werden können. Die christliche Religion ist unstreitig ein mächtiges Hülfsmittel zur Veredlung des Menschengeschlechtes: Ihre Moral ist rein einfach, erhaben, menschenfreundlich. Ein guter Christ, das heißt, ein Mensch, der nach den Grundsätzen des Evangeliums lebt, ist gewiß auch ein guter Bürger, ein nützliches Mitglied der bürgerlichen Gesellschaft ${ }^{184}$.

Butenschoen war dafür, die alten Religionen einer neuen Zeit anzupassen, nicht aber sie durch einen neuen Kult zu ersetzen. So erklären sich Artikel wie Die Bergpredigt Christi erklärt für Republikaner von geradem Sinn und reinem Herzen ${ }^{185}$ aus seiner Feder.

${ }^{182}$ Clubprotokoll vom 25. Dez. 1793, in: HeITZ, Les sociétés politiques, S. 316.

${ }^{183}$ Art. „Christus war kein Charlatan, wie ein ci-devant Propagandist sagte“, in: Argos, Nr. 3, 8 niv. II.

${ }^{184}$ Art. „Über den Zustand des Religionswesens im Niederrheinischen Departement“, in: Argos, Nr. 29, 5. Sept. 1793.

${ }^{185}$ Art. „Die Bergpredigt Christi erklärt für Republikaner von geradem Sinn und reinem Herzen", in: Argos Nr. 12, 4 pluv. II. 
Dies waren jedoch Stimmen einer Minderheit. Feindschaft gegenüber allem, was früher geglaubt worden war, war im innersten Kern der jakobinischen Führung die Regel. Das Feindbild des Priesters wurde auch für die Verfolgung relevant. Priester, die trotz des Kultverbots weiter praktizierten, wurden inhaftiert und der Justiz vorgeführt. Noch kurz vor dem Ende des Terrors beschlossen die Repräsentanten Hentz und Goujon, die Festnahme sämtlicher Priester durch den Einsatz von Militäreinheiten zu beschleunigen ${ }^{186}$. Die Distanz der Straßburgischen Bevölkerung zur jakobinischen Führung nahm durch diese Maßnahmen stetig zu. Dennoch führte die aggressive Religionspolitik im Osten nicht wie in der Bretagne ${ }^{187}$ oder den Pyräneen ${ }^{188}$ zu Aufständen. Die Bewohner der Rheinregion nutzten massenhaft die Möglichkeit zur Emigration, wodurch sich das Protestpotential verringerte.

Kurz nach dem Fest, am 4. Frimaire des Jahres II (24. November 1793), ordneten die Représentants du peuple Saint-Just und Lebas die Zerstörung der Statuen des ehemaligen Münsters und das Aufziehen der Trikolore auf der Turmspitze an ${ }^{189}$. Die endgültige Reinigung von den Zeichen des Alten folgte also der Schaffung der neuen republikanischen Zeichenwelt durch das Fest der Vernunft ${ }^{190}$.

Der Stadtrat, der mit der Umsetzung dieses Befehls befaßt war, stand nicht geschlossen hinter den zerstörerischen Maßnahmen. Nach einem späteren Bericht des deutschen Immigranten Georg Wedekind hatten nur der Bürgermeister Monet und der Munizipalbeamte Bierlyn für die Anordnung gesprochen $^{191}$. Im Sitzungsprotokoll vom 12. Frimaire (2. Dezember 1793) spiegeln sich Zweifel:

Sur le rapport de l'administrateur des travaux publics, que le drapeau tricolore étoit déjà arboré sur la dite tour, qu'il avoit donné aussi les ordres pour faire abattre toutes les statues isolées, placées á l'extérieur dudit temple, qu'une partie en étoit actuellement abattue, et que l'autre le seroit aussi vite que la rareté actuelle des ouvriers le permettroit; que quant au

${ }^{186}$ Repr. Goujon, HENTz, Beschluß vom 4 therm. II [Arch. Nat. Paris, AF II 135, doss. 1044, 14].

${ }^{187}$ T. TACKETT, The West in France 1789: The Religious Factor in the Origins of the Counterrevolution, in: JMH 54 (1982) S. 715-745.

${ }_{188}^{189}$ MCPHEE, Counter-Revolution in the Pyrenees.

189 Arrêtés des Représentants du peuple, an II [Arch. Dépt. Bas-Rhin, 6 L 44, Doss. St. Just/Lebas].

${ }^{190} \mathrm{Vgl}$. Elisabeth LIRIS, Le vandalisme révolutionnaire, in: Michel VovELLE, Antoine de BAËCQUE, Recherches sur la Révolution française, Paris 1991, S. 103-110; François SOUCHAL, Le vandalisme de la Révolution, Paris 1993.

${ }^{191}$ Georg WEDEKIND, Etwas vom Vandalismus in Strasburg, verübt im andern Jahr der Republik. Schreiben an Bürger Grégoire, Volksrepräsentant zu Paris von Georg Wedekind, im 3ten Jahre der fränkischen Republik, Straßburg 1794, S. 15 [Bibl. Nat. Univ. Str., M 10946]. 
grand nombre de statues qui font partie de l'architecture même et qui ne pourroient être enlevés sans dégrader l'édifice, il croyoit que la loi s'opposoit à leur démolition. Vû encore le décret de la Convention nationale du 6 juin 1793 qui prononce la peine de dewx années de fers contre quiconque dégradera les monumens nationaux, et oui le Procureur de la Commune, la Commission municipale a approuvé les mesures susdites prises par l'administrateur des travaux publics; elle a arrêté, qu'il en sera fait part auxdits Représentants du peuple, et qu'il leur sera observé en même tems, que l'édifice de la cathédrale tenant un rang distingué parmi les monumens nationaux, la Commission municipale croit que ce seroit contrevenir à la loi susdite en abattant les statues qui font partie de l'architecture dudit édifice, et qui ne pourroient en être enlevées sans le dégrader ${ }^{192}$.

In einem Brief ähnlichen Inhalts an die Représentants du peuple schlossen die Munizipalen sich ebenfalls prinzipiell der Meinung ihrer Vorgesetzten an, daß die Statuen an die alte Sklaverei erinnerten und so die alten Vorurteile perpetuierten, aber sie beriefen sich gleichzeitig auf das Gesetz vom 6. Juni 1793, das die Verschandelung von Kunstdenkmälern verbot ${ }^{193}$.

Der Bürgermeister Monet jedoch ließ, ohne seine Kollegen erneut zu konsultieren, am 14. Frimaire (4. Dezember 1793) die Order ausgeben, alle verdächtigen Statuen an der Fassade des Münsters zu zerstören ${ }^{194}$. An den Administrateur des travaux publics erging die Anordnung de requérir non seulement les ouvriers, mais les citoyens en état de se servir d'un marteau pour abattre le plus promptement possible toutes les statues du temple de la raison $^{195}$. Mit dieser Order setzte Monet genau das um, was die Représentants $d u$ peuple gefordert hatten ${ }^{196}$. Zwischen dem 17. und dem 19. Frimaire (7. bis 9. Dezember) verschwanden Statuen vor allem vom unteren Teil der Fassade. An den Portalen wurden die großen Standbilder abmontiert. Reliefs, die Bibelszenen darstellten, wurden abgeschlagen. Die drei Reiterstandbilder der Könige Chlodwig, Dagobert und Rudolph von Habsburg auf halber Höhe der Fassade wurden abgenommen. Die Tannenzapfen, welche die Firste der Kathedrale schmückten, wurden abgeschlagen, weil man sie für Lilienblüten hielt. Im Inneren der Kathedrale wurden der Hauptaltar und zwei Seitenaltäre abgetragen, die Kapellen in den Seitenschiffen ausgeräumt, die Kanzel abgenommen, Inschriften ausgemeißelt. Insgesamt fielen 235 Statuen der Zerstörung zum Opfer, knapp siebzig von ihnen blieben durch vorsichtiges Abneh-

\footnotetext{
${ }^{192}$ Registres du Corps Municipal, 12 frim. II (Art. 2167) [Arch. Mun. Str.].

${ }^{193}$ Copie de la lettre adressée par les membres composant la commission municipale de la commune de Strasbourg aux Représentants du peuple, en date du 13 frimaire an II, in: Livre Bleu, Pièces à l'appui Nr. 38, Bd. 1, S. 31f.

${ }^{194}$ Registre de présentation municipale, Nr. 3925, 14 frim II, St. 4, zit. nach Livre Bleu, Pièces à l'appui Nr. 38, 4, Bd. 1, S. 32.

${ }^{195}$ Ibid.

${ }^{196}$ Vgl. MONAR, Saint-Just, S. 471.
} 
men erhalten und konnten später wieder angebracht werden ${ }^{197}$. Im Sinne des Reinigungsgedankens hatte die jakobinische Verwaltung sich bemüht, der Kathedrale ein neues Gesicht zu geben. Alles an dem Gebäude, was an den „Aberglauben“ erinnerte, sollte verschwinden; übrig blieb eine schlichtere Form, die das Ende des „Fanatismus" und den Beginn des Zeitalters der Vernunft versinnbildlichen sollte.

Die Anbringung einer vier Meter hohen roten Mütze aus Blech auf der Spitze des Münsterturms stellte die letzte Baumaßnahme dar, die im Namen des Höchsten Wesens durchgefuhrt wurde; sie vollendete gleichsam die symbolische Übernahme des Münsters. Die Tage, als die Hämmer auf die Fassade des Münsters eingeschlagen hatten, lagen schon einige Monate zurück, als der Nationalagent des Straßburger Distriktes Mainoni in einem Brief an die Stadtverwaltungen mahnte, daß noch immer Zeichen des Feudalismus an Gebäuden prangten und daß viele Kirchtürme nach wie vor von Kreuzen überragt wurden. Er lud die Munizipalitäten aller Orte, wo noch solche Ueberreste des Aberglaubens oder irgend eine Spur von der alten, mit Recht verabscheuten Regierung könnten angetroffen werden, ein, dieselben sogleich wegzuschaffen, und an ihre Stelle Freyheits-Müzen anzubringen, welche so viel als möglich in die Augen fallen, damit der Reisende von weitem schon dieses Zeichen unsrer Unabhängigkeit unterscheiden könne, und damit der Anblick desselben das Herz jeden ächten Republikaners erquicke ${ }^{198}$. An den Stadtrat von Straßburg sandte er eine Anweisung, in der das Kreuz auf der Turmspitze des Tempels der Vernunft gesondert erwähnt wurde:

Il est plusieurs bâtimens publics en cette commune, qui blessent encore la vue du patriote par les signes de féodalité ou de superstition que les deshonorent [...] Le Temple de la raison même en offre de trop marquans du coté de la chapelle cidevant St. Laurent pour ne pas choquer l'œil du Republicain et sa tour est surmontée d'une croix qui ne peut convenir qu'aux temples du fanatisme, non a celui de la raison. Nous vous requerrons une dernière fois de faire disparoitre toutes les traces d'erreurs que le français a abjuré ${ }^{199}$.

Die Dekrete des Konvents, die eigentlich die Entfernung der Zeichen von royauté und féodalisme anordneten, wandte Mainoni also auch auf religiöse Symbole an.

${ }^{197}$ Die Liste der Zerstörungen ist einem im Original nicht mehr auffindbaren Protokoll vom 6 Germinal III entnommen, zit. nach Jean-Frédéric HERMANN, Notices historiques, statistiques et littéraires sur la ville de Strasbourg, Bd. 1, Strasbourg 1817, S. 384-387.

${ }^{198}$ Der National-Agent des Strasburger Distriktes an die Munizipalitäten des Bezirks [Arch. Mun. Str., Documentation des séances du Corps municipal 28, Doss. 515].

${ }^{199}$ Brief der Distrikts- an die Stadtverwaltung von Straßburg, 2 germ. II, in: Transcription des lettres expédiées par l'administration du district. 24 ventose-19 thermidor an II, [Arch. Dépt. Bas-Rhin, 6 L 48, Nr. 28]. 
Wenig später erreichte Mainoni die Weisung des Comité de salut public, die Lilienblüten, Waffen und Statuen der Könige nicht nur notdürftig abzuschlagen, sondern sie so zu beseitigen, daß il n'en subsiste pas même l'empreinte par la différence de la nuance de la pierre ${ }^{200}$. Falls dies nicht möglich sei, sollten die Stellen durch Symbole der Freiheit verdeckt werden. In dieser Anordnung war von religiösen Zeichen wiederum nicht die Rede; dies ist ein weiterer Beleg für die Zurückhaltung der Zentrale in religiösen Fragen. Mainoni leitete die Anweisung an die Munizipalitäten weiter und warnte diese vor weiterem Zeitverlust ${ }^{201}$. Nach dieser dritten Aufforderung reagierte die Straßburger Stadtverwaltung. Sie verteidigte nun ihrerseits ihr Vorgehen und bezeichnete die Anschuldigungen des Distriktsagenten als übertrieben ${ }^{202}$.

In bezug auf die Turmspitze hatte die Munizipalität die Expertise des Reçeveur de la fondation pour l'entretien du Temple de la Raison eingeholt, der einen Plan ausgearbeitet hatte, wie das Kreuz zu beseitigen sei; gleichzeitig wies dieser jedoch darauf hin, daß dieses Unternehmen aufwendig und kostspielig sei. Unter Berufung auf das Gesetz vom 6. Juli 1793 zum Schutz der alten Gebäude schickte der Stadtrat eine Rückfrage an die Distriktsverwaltung avec l'invitation de déterminer si ce morceau d'architecture doit être regardé comme un signe de superstition, ou non ${ }^{203}$. Diese Nachfrage hatte den einzigen Zweck, Zeit zu gewinnen, denn der Distrikt hatte sich mehrmals eindeutig geäußert. Die Stadtverwaltung suchte so nach Wegen, die Bausubstanz der Kathedrale zu retten. Der Distriktsrat ließ sich diesmal mit seiner Antwort einen knappen Monat Zeit, bestätigte dann aber, am 6. Floréal, seine ursprüngliche Anordnung. Er beharrte auf der Ausführung des Gesetzes vom 14. September 1793, das die Entfernung der Zeichen von Despotismus und Feudalherrschaft befohlen hatte ${ }^{204}$.

Der Stadtrat hatte nun eigentlich keine andere Wahl als die Abnahme des Kreuzes einzuleiten. Daß er es dennoch nicht tat und stattdessen das Aufsetzen der Jakobinermütze veranlaßte, ist ein Zeichen dafür, daß die vollständige Unterordnung der lokalen Gewalten unter die Anweisungen der Volksvertreter nicht mehr zu erreichen war. Zu seiner Rechtfertigung konnte er sich allerdings auf die erste Anordnung Mainonis und die Weisung des Comité de salut public vom 14. Vendemiaire berufen, in denen noch vom Anbringen von Frei-

${ }^{200}$ Le Comité de salut public aux Municipalités, 14 vent. II [Arch. Mun. Str., Documentation des séances du Corps municipal, 28, Doss. 516].

${ }^{201}$ Brief von Mainoni an die Munizipaliäten des Straßburger Distrikts, 9 germ. II, in: District de Strasbourg. Registre de Transcription des lettres expédiés par l'agent national du district. 24 niv.-13 germ. II, [Arch. Dépt. Bas-Rhin, 6 L 53, Nr. 404].

${ }^{202}$ Registres du Corps municipal, 12 germ. II (Art. 325) [Arch. Mun. Str.]

${ }^{203}$ Ibid.

${ }^{204}$ Délibérations et arrêtés de l'administration du district de Strasbourg, 6 flor. II [Arch. Dépt. Bas-Rhin, 6 L 14, Nr. 12407]. 
heitsmützen, bzw. von Symbolen der Freiheit die Rede $\operatorname{war}^{205}$. Die Arbeiten an der Mütze dauerten vom 23. Floréal bis 25. Prairial (12. Mai-13. Juni 1794) und kosteten die Stadt 2991 livres ${ }^{206}$. Mit der Beendigung der Arbeiten an der Jakobinermütze auf dem Straßburger Münster war die äußerliche Umgestaltung der Kathedrale abgeschlossen.

Die große Stunde der Jakobinermütze auf dem Münster war das von Robespierre verordnete Fest des Höchsten Wesens. A huit lieues de distance sur l'une et l'autre rive du fleuve, qui sépare le sol français de la terre de l'esclavage, on pouvoit appercevoir le bonnet de la liberté, placé au somet de la tour du temple, orné de rubans tricolores flottant dans l'imensité des airs ${ }^{207}$. Am 20. Prairial (8. Juni 1794) formierten sich die Straßburger Jakobiner und ihre Anhänger im Schatten der umgestalteten Kathedrale zu einem pittoresken Festzug. Wie beim Fest der Vernunft gipfelte das Fest in einem Gottesdienst zu Ehren des Höchsten Wesens.

Durch die Erschaffung des Vernunftskultes war ein neues Selbstverständnis entstanden. Nicht mehr nur Gegnerschaften bestimmten die radikale jakobinische Ideologie, sondern auch eine neue Einheit von Gott, Politik und Gesellschaft. Diese stellte in gewisser Weise die metaphysische Überhöhung des revolutionären Glaubens an politischen Konsens, Einheit und Einheitlichkeit der Gesellschaft dar. Durchgesetzt wurde sie mit Gewalt: Erste Schritte zur neuen Einheit waren die symbolische Erneuerung durch eine Reinigung der Zeichen und eine Säuberung des Volkskörpers von gefährlichen Elementen. Der Wille zur Erneuerung hatte jedoch kein präzises politisches Ziel. So wie sich reale politische Gegner in imaginäre verwandelten, hatten sich konkrete politische Ziele in diffuse verwandelt. Der Kampf der guten Revolution mit der bösen Gegenrevolution hatte sich verselbständigt. Statt konkreter Programme gab es jetzt eine unbestimmte Heilserwartung, die jede Art von politischer Aktion zu rechtfertigen in der Lage war.

Die Feinde der Jakobiner waren die Angehörigen der Verschwörung; sie waren an äußeren Merkmalen wie eben der Zugehörigkeit zur alten Religion zu erkennen. Durch die Erhebung des Jakobinismus zur Religion wurde nicht nur die Feinddefinition, sondern auch die Selbstdefinition vom Politischen ins Kulturelle übertragen. Die Jakobiner, die sich am Anfang ihrer Geschichte als rein politische Gruppierung verstanden hatten und jede Bindung an eine kulturelle Gruppe geleugnet hatten, verwandelten sich jetzt in eine fanatische reli-

${ }^{205} \mathrm{Daß}$ diese Vorgehensweise durchaus außergewöhnlich war, zeigt sich im Vergleich mit anderen Städten; in Landau wurde beispielsweise das Kreuz der Augustinerkirche abgeschlagen bevor es durch eine Jakobinermütze ersetzt wurde (Michael MARTIN, Revolution in der Provinz. Die Französische Revolution in Landau und der Südpfalz, Landau 1995, S. 68).

${ }^{206}$ Registres du Corps muncipal, 9 therm. Il (Art. 144) [Arch. Mun. Str.].

${ }^{207}$ Procès-verbal et Descripition de la fête de l'être suprême, célébrée le 20. Prairial, 27 prair. II [Bibl. Nat. Univ. Str., M 121595]. 
giöse Bewegung. Der Schluß- und Höhepunkt der Radikalisierung war damit erreicht.

\section{Die Erneuerung der Judenfeindschaft}

Daß der radikale Jakobinismus, der sich zum Feind aller alten Religionen erklärt hatte, auch antisemitische Züge hatte, kann kaum verwundern. Seit der Verabschiedung der Verfassung von 1791, welche den Juden die vollen Bürgerrechte zusprach, bedienten sich die judenfeindlichen Kreise in Straßburg neuer Argumente. Den Juden wurde nun angelastet, daß sie sich, obwohl sie durch die Revolution so viel gewonnen hätten, nicht ausreichend für das Gemeinwohl engagierten. Obwohl man ihnen die Gewerbefreiheit gegeben habe, widmeten sie sich weiterhin den alten Formen des Gelderwerbs. Sie seien nicht bereit, in „ehrliche Berufe" zu wechseln. Sie schickten ihre Söhne nicht in den Krieg und brächten auch sonst keine Opfer für das Vaterland. Darüber hinaus verübelte man ihnen ihre Erfolge als Lieferanten der Armeen ${ }^{208}$. Selbst Spenden von Juden für die Armeen wurden argwöhnisch begutachtet; im September 1793 schickte beispielsweise eine Kommission der Munizipalität vom Juden Cerf Berr gespendeten Wein zurück, weil er zu schlecht für die Verteidiger des Vaterlandes sei und kritisierte dieses garstige und filzige Betragen $^{209}$.

Die Kampagne des Clubs für die Emanzipation der Juden vom Februar 1790 war nur von kurzer Dauer gewesen; doch auch nach ihrem Ende machten sich einzelne Straßburger Jakobiner die Verteidigung der Juden gegen die neuartigen Vorwürfe zur Aufgabe. Es waren vor allem der Straßburger Kurier, die deutsche Ausgabe des Courrier de Strasbourg, und der Argos, welche Verteidigungsschriften von und für Juden abdruckten und sich bemühten, Beispiele für jüdischen Patriotismus zu liefern. Der Straßburger Kurier berichtete beispielsweise von einer Übung im Rahmen der levée de 300.000, bei der alle Bürger unter Waffen auf der Place des Armes zu erscheinen hatten: Wir dürfen nicht vergessen anzuzeigen, daß auch die Juden, obschon es der Sabbat war, bewafnet bei ihren Bataillons erschienen, und sich nicht weniger bereit zeigten, ihre Pflichten als freie Bürger zu erfüllen ${ }^{210}$. Wenig später rechtfertigte dasselbe Blatt die Juden Marx Berr und Baruch Cerf Berr, welche von General Custine beschuldigt wurden, eigenmächtig in Worms ein Mehllager für die

${ }^{208}$ Rodolphe REUSS, L'Antisemitisme dans le Bas-Rhin pendant la Révolution 1790-93. Nouveaux documents inédits, in: REJ 78 (1914) S. 246-263; Monique-Lise COHEN (Hg.), Les juifs ont-ils des cœurs? Discours révolutionnaire et anti-semitisme, Andouque 1992.

${ }^{209}$ Art. „Strasburg“, in: Straßburgische Zeitung, Nr. 216, 11. Sept. 1793.

${ }^{210}$ Art. "Strasburg, den 12ten Merz“, in: Straßburger Kurier, 13. März 1793. 
Armee errichtet und so leichtfertig den Feinden Nahrungsmittel in die Hand gespielt zu haben ${ }^{211}$.

Die Auseinandersetzung verschärfte sich, als im Weltboten vom 1. Mai 1793 ein antisemitischer Artikel erschien. Darin wurden die Juden als Schädlinge der republikanischen Wirtschaft dargestellt. Der Straßburger Kurier druckte eine ausführliche Gegendarstellung, in der er den Redakteuren des Weltboten vorwarf, einen Aufruf zum allgemeinen Menschenhaß verfaßt zu haben:

Kaum hat man des Israeliten Fesseln zerbrochen, und ihm Plaz den Athem zu hauchen vergönnt, schreien schon alle Menschenfeinde: schließt die Fesseln wieder zu. - Mitbürger, eure Eltern haben 500 Jahre zugebracht, bis sie dieses Volk von dem Gipfel des Menschenglücks in den Abgrund des Elends geworfen, und ihr wollet in dem ersten Augenblik, da ihr ihm die Hand reicht, daß es so zivilisiert seyn soll, wie ihr, die ihr nie von dem Glüksstern gewichen seyd. Menschen, wo denkt ihr hin! Es ist genug davon, der Menschenfreund hat Stoff genug zum Nachdenken ${ }^{212}$.

Der Autor des Kuriers rief zur Geduld auf: Lasset sie ihr Glück als Menschen eine Zeit lang genießen, dann werdet ihr sehen, daß ihr auch Menschen gebildet habt. Es ist keine Gnade, die ihr ihnen gebt, es ist nur Gerechtigkeit, wenn ein Mensch zum anderen spricht: 'Ich will dich nun als Mensch erkennen, nachdem ich dich 800 Jahre in Ketten gehalten habe.' Brüder! freie Franken, fühlt es! $!^{213}$

Der Weltbote reagierte wiederum mit wütenden Angriffen, was der Straßburger Kurier mit einer Sonderbeilage zum Thema quittierte, in der es hieß: Ich glaubte es mit einem braven Manne zu thun zu haben, der nur durch Vorurtheil verblendet sei; allein ich sehe nun leider, daß ich mit einem Starrkopfe zu kämpfen habe, der mit allen Talenten, die ein spanischer Inquisitor besizen muß, ausgerüstet ist ${ }^{214}$. Auf den Vorwurf des Weltboten, daß sie [die Juden] in diesen Tagen noch glauben, daß alles, was die andern Religionsparteien besitzen, ihnen angehöre, und von diesen nur usurpirt seie, daher sie sich auch jeden Betrug gegen sie erlauben ${ }^{215}$, antwortete der Kurier, allen Gläubigen, egal welcher Religion, müsse es darauf ankommen, durch gute Taten Gott zu gefallen; das gelte auch fur die Juden. Auf die Anklage, daß es dem Juden recht sehr zu verargen sei, wenn er mit Haß und Wuth gegen seine Verfolger

\footnotetext{
${ }^{211}$ Art. „Strasburg“, in: Straßburger Kurier, 21. April 1793.

${ }^{212}$ Art. „Vertheidigung der jüdischen Moral gegen die Angriffe des Weltbothen“, in: Straßburger Kurier, 8. Mai 1793.

${ }^{213}$ Ibid.

${ }^{214}$ Art. „Abgedrungene Antwort auf des Weltboten erstes und leztes Wort über die Juden, meinen Mitbürgern zur unpartheischen Beurteilung dargelegt", in: Beilage zum Straßburger Kurier, 25. Mai 1793.

${ }^{215}$ Ibid.
} 
um sich siehet, weil die Verfolgung die Folge seiner schlechten Aufführung ist $^{216}$, entgegnete der Kurier, der Weltbote habe Ursache und Folge verwechselt; die Juden seien durch die jahrhundertelange Verfolgung geprägt.

Der Argos, im Sommer 1793 immer noch das wichtigste deutschsprachige Blatt des Straßburger Jakobinismus, beteiligte sich an der Verteidigung der Juden. Am 16. Juli 1793 erschien ein langer Artikel in mehreren Fortsetzungen. In diesem Artikel beschrieb der Redakteur Schneider die Haltung gegenüber den Juden seit der Verleihung der Menschenrechte. Schneider erkannte es durchaus als Problem, daß die Juden auch nach ihrer Befreiung nicht Feldbau, Handwerk, und andere nützliche Gewerbe betrieben, sondern vom Unterhandeln oder Schmutzen, vom Assignatenwucher und ähnlichen verdächtigen Gewerben leben müßten ${ }^{217}$. Der Unwillen gegen die Juden sei wieder aufgekommen, weil diese als Lieferanten der Armee in Konkurrenz zu Nicht-Juden getreten seien. Die Konkurrenten der Juden ermangelten nicht, die Juden überhaupt bei ihren Bekannten und Anhängern zu lästern; und so vermehrte sich die Anzahl der Judenfeinde mit jedem Tage ${ }^{218}$. Der Argos führte gegen diese Vorwürfe die Prinzipien der Gleichheit und der Religionsfreiheit ins Feld: Lehrt die jüdische Religion etwas, das der bürgerlichen Verfassung zuwider wäre? Hindert sie die Ausübung der bürgerlichen Pflichten? Nein; die Moral des alten Testaments ist rein ${ }^{219}$. Mit diesem Argument erinnerte Schneider an die Auffassung der frühen Clubbisten über das Verhältnis von Politik und Religion.

Wenig später rückte Schneider den Brief eines aus Mannheim stammenden und in Uffholz lebenden Juden ein. Dieser zeigte sich bestürzt, daß sich einige Jakobiner für die Vertreibung der Juden ausgesprochen hatten: Wo ist denn die angepriesene Toleranz... nicht Toleranz, sondern die heilige Bruderliebe, die ihr beschworen habt, die ihr täglich aufs neue beschwört, und für die ihr täglich Ströme Bluts vergießet! ${ }^{220}$ Der Autor wies auf das Engagement der Juden für das Allgemeinwohl hin. Eine grundsätzliche Veränderung ihres Charakters sei in wenigen Jahren nicht zu erwarten ${ }^{221}$; es bedürfe dazu eines Prozesses der Umerziehung: Eure Pflicht ist es vielmehr, die ihr ihnen so viele Menschenalter von Vollkommenheit und bürgerlichen Tugenden geraubt habt, zu ihrer Besserung und Veredelung, so viel an euch ist, beizutragen. Erwartet den Au-

\footnotetext{
216 Ibid.

${ }^{217}$ Art. „Ueber die Juden. Eine Beilage von Eulogius Schneider.“, in: Argos, Nr. 7, 16. Juli 1793.

${ }^{218}$ Ibid.

${ }^{219}$ Ibid.

${ }^{220}$ Art. ,Schreiben an den Bürger Eulogius Schneider, öffentlichen Ankläger des Niederrheinischen Departements.“, in: Argos, Nr. 9, 20. Juli 1793.

${ }^{221}$ Fortsetzung, in: Argos, Nr. 10, 23. Juli 1793.
} 
genblick, wo die National-Convention Frankreich mit einer NationalErziehung beschenken wird ${ }^{222}$.

Mit dem Beginn des Terrors wurden alle Mahnungen zu einer Politik der Toleranz hinfällig. Die Angriffe gegen Juden, auch aus den Reihen der Jakobiner, wurden häufiger; der Druck auf die Vertreter abweichender Meinungen wuchs. Es war die seit dem Herbst in Straßburg einsetzende religiöse Erneuerung des Jakobinismus, welche den Rahmen für die Verschärfung der Judenfeindschaft darstellte. Die Einführung des Vernunftkultes ging mit der Abschaffung aller Religionen, also auch des Judentums, einher.

Am 2. Frimaire (22. November 1793) beschloß der Distrikt von Straßburg gegen den jüdischen Kult vorzugehen. Die Begründung für diesen Schritt lautete:

Il existe parmi ces hommes la loi inhumaine d'opérer sanguinairement sur l'enfant mâle qui nait, comme si la nature n'étoit pas parfaite: c'est un outrage à la divinité. Ils portent la barbe longue par ostentation et pour singer les patriarches desquels ils n'ont pas hérité les vertus. Ils pratiquent une langue qu'ils ne connoissent pas et qui n'est plus usitée depuis longtems. En conséquence je requiers la Commission provisoire de leur interdire ces usages et d'ordonner qu'un autodafé sera fait à la vérité de tous les livres hébreux et principalement du Talmuth, dont l'auteur a été assés frippon de leur permettre de prêter à usure aux hommes qui ne seraient pas de leur croyance $^{223}$.

In der Terreurzeit wurden die Juden weiterhin als schlechte Bürger und "Schädlinge“ der Wirtschaft bezeichnet. Die meisten Berichte über die schlechte Wirtschaftslage verwiesen auf den schädlichen Einfluß jüdischer Händler, Wechsler und Wucherer. Moyennant leurs ruses ordinaires ils parviennent à se soustraire de tous les convois et réquisitions ils sement des inquiétudes pour en tirer profit ${ }^{224}$, hieß es in einem Bericht. An anderer Stelle wurde gefordert:

Il est encore un autre genre de mal qu'il faut déraciner, c'est l'usure et l'agiotage des juifs. Ces citoyens sont absolument incorrigibles quoiqu'ils aient la faculté d'acheter des biens etc.; plutot que de travailler, ils préférent de continuer de vivre à leur ancienne manière en exerçant l'usure et l'agiotage; on peut les comparer aux bourdons dans les ruches mangeant le miel des abeilles sans travailler ${ }^{225}$.

${ }^{222}$ Fortsetzung, in: Argos, Nr. 12, 27. Juli 1793.

${ }^{223}$ Sitzung des Distrikts vom 2 frim. II, in: Livre Bleu, Pièces à l'appui Nr. 94, Bd. 2, S. 200.

${ }^{224}$ Bericht von Daniel STAMM [Arch. Nat. Paris, AF II 135, Doss. 1041, 5].

${ }^{225}$ GOTTEKIEN, Aperçu [Arch. Nat. Paris, AF II 135, Doss. 1041, 6]. 
Eine Straßburger Adresse an den Wohlfahrtsausschuß forderte: Il a paru également utile d'éloigner des trois dep.ts tous les juifs, riches sans propriétés ou ceux qui n'auront pas une profession manuelle quelconque. Ce sont eux seuls qui sont les auteurs de tout l'agiotage qui se fait ouvertement ${ }^{226}$.

Mit diesen Schuldzuweisungen gingen Vorschläge zu Gewaltmaßnahmen gegen Juden einher. Der Repräsentant Baudot schlug vor: Ne seroit il pas convenant de s'occuper d'une régénération guillotinière à leur égard? ${ }^{227}$ Bereits im Oktober beschloß die Société, den Repräsentanten vorzuschlagen, mit allen „unnützen Mündern“ auch die Juden aus der Stadt zu verbannen ${ }^{228}$. Dieser Beschluß wurde nicht umgesetzt, doch Saint-Just ließ eine Reihe von Juden verhaften $^{229}$. Im Frühjahr 1794 wurde im Jakobinerclub erneut über eine Verbannung der Juden aus dem Land der Freiheit nachgedacht ${ }^{230}$. Diese Äußerungen zeigen, daß die jakobinische Judenfeindschaft sich vor allem zweier Argumente bediente: Zum einen wurden die Juden wegen ihrer durch die Religion bedingten Eigenheiten angefeindet, zum anderen, weil sie als „Schädlinge" der Wirtschaft angesehen wurden. Das emanzipatorische Moment, das die frühen Selbst-und Feinddefinitionen der Jakobiner geprägt hatte, war ganz in den Hintergrund getreten.

\footnotetext{
${ }^{226}$ Repr. GARNERIN, Aux membres du Comité de salut public, 5 mess. II [Arch. Nat. Paris, AF II 135, 1040, 16].

${ }^{227}$ Brief BAUDOT vom 29 Brum. II, in: Livre Bleu, Pièces à l'appui Nr. 36, Bd. 2, S. 127.

${ }^{228}$ Beschluß der Sociéte vom 17. Okt. 1793, in: Livre Bleu, Bd. 2, S. 304.

${ }^{229}$ SAINT-JUST, CEuvres complètes, Paris 1984, S. 579.

${ }^{230}$ Clubprotokoll vom 3. Mai 1794, in: HEITZ, Les Sociétés politiques, S. $346 f$.
} 